\title{
The sensitivity of secondary organic aerosol component partitioning to the predictions of component properties - Part 1: A systematic evaluation of some available estimation techniques
}

\author{
G. McFiggans, D. O. Topping, and M. H. Barley \\ Centre for Atmospheric Sciences, School of Earth, Atmospheric and Environmental Sciences, University of Manchester, \\ Manchester, M13 9PL, UK
}

Received: 21 May 2010 - Published in Atmos. Chem. Phys. Discuss.: 22 June 2010

Revised: 5 October 2010 - Accepted: 18 October 2010 - Published: 3 November 2010

\begin{abstract}
A large number of calculations of the absorptive partitioning of organic compounds have been made using a number of methods to predict the component vapour pressures, $p^{0}$, and activity coefficients, $\gamma_{i}$, required in the calculations. The sensitivities of the predictions in terms of the condensed component masses, volatility, O:C ratio, molar mass and functionality distributions to the choice of $p^{0}$ and $\gamma_{i}$ models and to the number of components to represent the organic mixture have been systematically compared. The condensed component mass was found to be highly sensitive to the vapour pressure model, and less sensitive to both the activity coefficient model and the number of components used to represent the mixture although the sensitivity to the change in property estimation method increased substantially with increased simplification in the treatment of the organic mixture. This was a general finding and was also clearly evident in terms of the predicted component functionality, $\mathrm{O}: \mathrm{C}$ ratio, molar mass and volatility distributions of the condensed organic components. Within the limitations of the study, this clearly demonstrates the requirement for more accurate representation of the $p^{0}$ and $\gamma_{i}$ of the semi-volatile organic proxy components used in simplified models as the degree of simplification increases. This presents an interesting paradox, since such reduction in complexity necessarily leads to divergence from the complex behaviour of real multicomponent atmospheric aerosol.
\end{abstract}

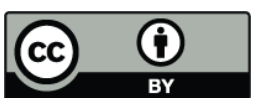

Correspondence to: G. McFiggans (g.mcfiggans@manchester.ac.uk)

\section{Introduction}

Aerosol particles remain highly uncertain contributors to climate change, influencing climate directly by the scattering and absorption of solar radiation and indirectly through their role as cloud condensation nuclei; the latter effect contributing the greatest remaining uncertainty in the atmosphere radiative forcing (IPCC, 2007). Both inorganic and organic material can transfer between the gas and particle phase. Whilst inorganic material is restricted to a relatively few relatively well-understood compounds, the organic fraction can comprise many thousands of, as yet largely unidentified, compounds with a vast range of properties (e.g. Zhang et al., 2007; Hallquist et al., 2009 and references therein). There have been tens to hundreds of thousands of organic components isolated in the atmosphere (Goldstein and Galbally, 2007; Lewis et al., 2000; Hamilton et al., 2008; Hallquist et al., 2009) and near explicit (Bloss et al., 2005a,b) and explicit (Aumont et al., 2005) models of oxidative degradation of gaseous VOCs predict the existence of many thousands to tens of millions of components. Conversely, aerosol schemes in large-scale models necessarily ignore the vast complexity of the organic mixture and will continue to do so in the future. This is a result of prohibitive computational expense that can only be reduced via a reduction in complexity (numerical, chemical or both). In order to better quantify the impacts of aerosol processes on climate and air quality it is necessary to improve the quantitative prediction of gas/aerosol partitioning and aerosol water content. The latter is necessary for predicting the direct and indirect climatic effect; the former determines the evolving chemical composition of the aerosol and is necessary for predicting aerosol loading and composition. Field measurements demonstrate that theoretical estimates of secondary organic aerosol (SOA) masses may

Published by Copernicus Publications on behalf of the European Geosciences Union. 
be 1 to 2 orders of magnitude too low (Heald et al., 2005). Many factors influence the SOA yield, including the mass of organic aerosol that can serve as a condensing medium (Pankow, 1994; Odum et al., 1996), acid catalysed and other chemical reactions in the particulate phase (Jang and Kamens, 2001; Iinuma et al., 2004; Kalberer et al., 2004), ambient humidity (Seinfeld et al., 2001; Jonsson et al., 2006) and temperature (Stanier et al., 2007; Johnson and Marston, 2008). Whilst by no means the only consideration, it has long been considered that a primary driver for the transfer of organic material between the gas and condensed particulate phase is the vapour pressure of each of the partitioning components above the particulate composition. This is dependent on the vapour pressure of each compound in its pure state $\left(p_{i}^{0}\right)$ (vapour pressure of component $i$ above pure liquid (or sub-cooled liquid) $i$ ), multiplied by the component activity $\left(a_{i}=\gamma_{i} x_{i}\right.$, the product of its activity coefficient and mole fraction) or "effective" concentration in the complex mixture of components using an appropriate reference state. This is implicitly embodied in the widely used equilibrium absorptive partitioning theory (Pankow, 1994; Odum et al., 1996; Pankow et al., 2001).

This study uses absorptive partitioning to describe the gas/particle partitioning in a complex multicomponent system, accounting for component interactions in the condensed phase (deviations from Raoult's Law) and the volatility of the pure components. The amount of condensed material is calculated by summing all components, ensuring mass balance between the two phases for each component. Calculation of the partitioning requires a vapour pressure value, $p_{i}^{0}$, for all condensing compounds $i$, and the non-ideal deviations from Raoult's Law embodied in their $\gamma_{i}$ values.

Barley and McFiggans (2010) recently presented a comparison of boiling point and vapour pressure prediction techniques that have been used to model atmospheric aerosol loadings. Using the widest available range of low volatility multifunctional organic benchmark compounds of measured vapour pressures to assess the technique skill, they provided a critical evaluation of the methods and recommendations for appropriate technique choice for atmospheric applications. The range of vapour pressure deviations from the experimentally-determined values was shown to be many orders of magnitude, with the greatest discrepancies resulting from the choice of boiling point predictive method. The sensitivity of absorptive partitioning particulate mass calculations to the errors in the techniques was investigated for the experimental test compounds. It was found that the different predictive methods for boiling points introduced such variability that either negligible or very significant condensed organic mass was predicted. Whilst the compounds investigated by Barley and McFiggans (2010) were selected for their multifunctionality and very low experimental vapour pressures, they were still $\sim 100$ to 1000 times more volatile than compounds expected to condense significantly under typical ambient conditions. It is important to establish whether such boiling point (and hence vapour pressure) sensitivity of condensed mass is exhibited in simulations of complex mixtures of partitioning compounds with more atmospherically representative properties.

Raatikainen and Laaksonen (2005) presented a discussion of activity coefficient models that have been used to account for multicomponent aerosol non-ideality. Group contribution methods include the widely used UNIFAC model and its variants (Fredenslund et al., 1975; Yan et al., 1999). Much effort has been directed towards improvement in the accuracy of these models for atmospherically significant functionalities and temperatures through parameter re-evaluation (Peng et al., 2001; Marcolli and Peter, 2005; Zuend et al., 2008). Although inclusion of inorganic ions within such frameworks is not straightforward, there are a number of models that aim to account for organic-inorganic molecular interactions via extended Debye-Hückel methods and midrange interaction terms (e.g. Marcolli and Peter, 2005; Zuend et al., 2008; Clegg et al., 2008; Yan et al., 1999). Outstanding considerations associated with such models include the requirement for complex reference state corrections, which can limit applicability in mixed phase systems. Recently developed models such as AIOMFAC, for example, have been designed to obviate this requirement and can be used to predict phase separation for limited sets of organic functionality (e.g. Zuend et al., 2008).

Whilst each vapour pressure and activity coefficient model may carry its own advantages and disadvantages, a systematic evaluation of the techniques for atmospheric purposes is complex. This restricts the objective selection of a simplified representation of organic components that will make a dominant contribution to particulate mass or properties. Models of atmospheric oxidative degradation of volatile organic compounds (VOCs) range extensively in complexity of representation of the organic components depending on the scale of their application. In order to better assess the skill of such models in capturing the production of important SOA precursors it is necessary to systematically evaluate the ability of the varying complexity to reproduce the determinant properties of the most complex representation. Furthermore, to assess the ability of absorptive partitioning to capture the important characteristics of atmospheric SOA behaviour, a broader set of metrics than simple prediction of the condensed mass is required. Briefly, in addition to mass, these comparison metrics include component mass loadings (for comparison with e.g. mass spectral parent ion fragment distribution and molecular identification, see e.g. Hamilton et al., 2008), component volatility distribution for comparison with thermodenuder characterisations (see e.g. Huffman et al., 2009), O:C ratio for comparison with emerging measurements from online higher resolution MS (e.g. DeCarlo et al., 2006), molar mass distribution for comparison with determinations from e.g. osmometry or size-exclusion chromatography and examplarily illustrated using component functionality. 
Equilibrium absorptive partitioning itself has certain limitations. There is good reason to assume that instantaneous equilibrium will not pertain within an atmospheric aerosol. Uptake of gaseous components to (and their evaporation from) a particle population is a kinetic process, driven by a gradient between the background gaseous concentration and that at the surface of each particle. The number of collisions of molecules that can partition by condensation and evaporation with the particle surfaces depends on the size distribution of the particles and their probability of being accommodated into each particle. Under tropospheric conditions, the resultant mass transfer is normally in the so-called transition regime between free molecular and continuum mass transfer as may be calculated by flux-matching descriptions (e.g. Fuchs and Sutugin, 1971) or more approximate formulations (e.g. Schwartz, 1986). Mass transfer rates of gases to reasonable ambient populations in a range of environments may result in gaseous e-folding lifetimes of several tens of minutes to days (e.g. Bloss et al., 2005c; Haggerstone et al., 2005; Coe et al., 2006; Sommariva et al., 2006; Emmerson et al., 2007; Williams et al., 2007; Allan et al., 2009) depending on uptake probability (the mass accommodation coefficient contribution to this being the same in condensation and evaporation), indicating that disequilibrium may pertain over such timescales simply as a result of gaseous mass transfer limitations. Furthermore, heterogeneous and condensed phase reaction can further perturb the equilibrium leading to supersaturation of a component in either the gas or aerosol. Notwithstanding the implications of such dynamic processes and dependence on condensed phase kinetics, a basis for the determination of the equilibrium contributions to the particulate composition is required to calculate the equilibrium loading to form the basis for investigation of such dynamic deviation from equilibrium.

The aim of this paper is to investigate the sensitivity of SOA predictions to calculated properties $\left(\gamma_{i}, p_{i}^{0}\right)$ and the complexity of the representation of the organic aerosol fraction. A flexible framework for the evaluation is constructed, the techniques to be evaluated are briefly described and the evaluation metrics defined. The results are evaluated in terms of these metrics and limitations in VOC degradation mechanism reduction for SOA prediction are discussed. Two companion manuscripts examine (i) the sensitivity of properties of particulate material produced by absorptive partitioning (Topping et al., 2010) and (ii) the relative contribution to the condensed material from compounds generated using a complex VOC oxidative degradation model (Barley et al., 2010). It is not the intention here to investigate mixtures of organic components that will necessarily be found in the atmosphere; this is more comprehensively achieved in the latter manuscript identified above. The intent of the current study is to investigate a number of property estimation techniques that have been used in atmospheric applications in a framework for calculation of the absorptive partitioning of semi-volatile secondary organic aerosol components. In order to make such the evaluation more useful in an atmospheric context, the methodology we employ aims to a systematically explore the sensitivity under conditions (temperature, relative humidity and predicted total condensed mass) that may be broadly expected and for components that have broadly the degree of functionalisation and property spectrum (O:C ratio, volatility etc.) that might be found in the atmosphere. This is to overcome the current limitation that most, if not all, of the property estimation techniques have been developed for, and extensively applied to, conditions of the chemical process industries and technique evaluation under such very different conditions are less likely to be valid for atmospheric purposes.

\section{Methodology}

A large number of calculations of the absorptive partitioning of organic compounds were performed using a number of methods to predict the required pure component vapour pressures $\left(p^{0}\right)$ and activities $\left(x_{i} \gamma_{i}\right)$. The sensitivities of the predictions in terms of the condensed component masses, volatility distributions, O:C ratio, molecular weight and functionality to the choice of $p^{0}$ and $\gamma_{i}$ models, to the number of components to represent the organic mixture and to ambient environmental $\mathrm{T}$ and $\mathrm{RH}$ were systematically evaluated.

\subsection{Formulation of the partitioning model}

The molar based partitioning model used here is identical to that presented in Barley et al. (2009) and yields identical results to the conventional mass based model of Pankow (1994) whilst allowing use of mole fraction based activity coefficients with a conventional reference state unlike the model variant presented by Donahue et al. (2006). The partitioning constant $K_{p, i}$, in units of $\mathrm{m}^{3} \mu \mathrm{mol}^{-1}$ is given by Eq. (1):

$K_{p, i}=\frac{C_{i}^{\mathrm{cond}}}{C_{i}^{\mathrm{vap}} C_{\mathrm{OA}}}=\frac{R T f}{10^{6} \gamma_{i} p_{i}^{0}}$

where $C_{i}^{\text {vap }}$ is the vapour phase molar concentration of component $i, \mu \mathrm{molm}^{-3}$,

$C_{i}^{\text {cond }}$ is the condensed phase molar concentration of component $i, \mu \mathrm{molm}^{-3}$,

$C_{\mathrm{OA}}$ is the total molar concentration of condensed organic material, $\mu \mathrm{mol} \mathrm{m}^{-3}$,

$p_{i}^{0}$ is the saturated vapour pressure of component $i$, atm,

$R$ is the ideal gas constant $=8.2057 \times 10^{-5} \mathrm{~m}^{3} \mathrm{~atm} \mathrm{~mol}^{-1} \mathrm{~K}^{-1}$,

$T$ is the temperature, $\mathrm{K}$

$f$ is the fraction of the condensed material that may be considered absorptive, usually considered unity for most absorptive partitioning calculations and $\gamma_{i}$ is the activity coefficient for component $i$ in the liquid phase. 
Defining a partitioning coefficient $\xi_{i}$ for compound $i$ given its $K_{p, i}$ value:

$\xi_{i}=\left(1+\frac{1}{K_{p, i} C_{\mathrm{OA}}}\right)^{-1}$

where the total molar concentration of condensed organic material, $C_{\mathrm{OA}}$, is given by the sum of the products of the individual total component concentrations in both phases and their partitioning coefficient:

$C_{\mathrm{OA}}=\sum_{i} C_{i} \xi_{i}$

where $C_{i}=C_{i}^{\mathrm{vap}}+C_{i}^{\mathrm{cond}}$ is the total loading of component $i, \mu \mathrm{mol} \mathrm{m}^{-3}$.

The formulation is slightly more numerically efficient than that presented by Pankow (1994) and Pankow et al. (2001) in that the mass is only evaluated once at the end of the partitioning calculation rather than evaluating the number averaged molar mass of the condensed material within each iteration of the solver. Such efficiency savings would not normally be important, but the many tens of thousands of partitioning calculations for complex mixtures made in the current study require such minor optimisations.

\subsection{Vapour pressure and activity coefficient models}

The impacts of a limited number of combinations of property prediction techniques were conducted to establish a representative range of sensitivities using methods that have been reasonably widely employed in an atmospheric context.

The vapour pressure estimation methods evaluated in this study require two part calculation: estimation of normal boiling point $\left(T_{\mathrm{b}}\right)$ followed by extrapolation from $T_{\mathrm{b}}$ down to the temperature of interest. For compounds likely to be of atmospheric importance, the estimated $T_{\mathrm{b}}$ can be in excess of $700 \mathrm{~K}$, so relatively small error in the slope of the line between $T_{\mathrm{b}}$ and $25^{\circ} \mathrm{C}$ can result in a large error in predicted vapour pressures. The $T_{\mathrm{b}}$ estimation methods that have been used within atmospheric literature and are evaluated here are the methods of (i) Nannoolal et al. (2004) (used in E-AIM: Extended Aerosol Inorganics Model, http://www.aim.env. uea.ac.uk/aim/ddbst/pcalc_main.php; see Wexler and Clegg, 2002); (ii) Stein and Brown (1994), used in both E-AIM and EPI-Suite (EPA, 2009) and (iii) Joback and Reid (1987), used in the study of Camredon and Aumont (2006). These will henceforth be referred to as the N, SB and JR methods respectively. All were group contribution methods of varying complexity. The simplest is the JR method including 41 groups; SB is adapted from JR with additional groups (85 in total) and a correction for high boiling point values. $\mathrm{N}$ includes both primary and secondary groups (130+) along with group interactions (207 terms in total). The $\mathrm{N}$ method gave the best results when tested against experimental vapour pressure data for 45 multifunctional compounds. JR was consistently shown to overestimate the $T_{\mathrm{b}}$ values of a limited number of multifunctional compounds with predicted $T_{\mathrm{b}}>500 \mathrm{~K}$ in Barley and McFiggans (2010) compared with laboratory measured values.

The $p^{0}$ methods used in this work were that of Nannoolal et al. (2008) and Myrdal and Yalkowsky (1997) - henceforth referred to as the N/VP and MY methods. The N/VP method uses the same complex group contribution structure as the $T_{\mathrm{b}}$ estimation method. E-AIM calculates $p^{0}$ using $T_{\mathrm{b}}$ by $\mathrm{SB}$ combined with the vapour pressure by MY; or $T_{\mathrm{b}}$ by $\mathrm{N}$ with vapour pressure by N/VP or the method of Moller et al. (2008). Camredon and Aumont (2006) use JR-MY. All techniques for estimating boiling point $\left(T_{\mathrm{b}}\right)$ and vapour pressures $\left(p^{0}\right)$ have been described in detail and assessed in Barley and McFiggans (2010) along with two methods that did not require $T_{\mathrm{b}}$ estimation (Capouet and Müller, 2006; Pankow and Asher, 2008). These latter methods are not evaluated here because of the restricted functionality they cover. The Moller et al. (2008) method was not evaluated because of structural problems associated with excessive group increment contributions with multiple similar groups (Compernolle et al., 2010). It should be noted that Barley and McFiggans (2010) showed that the MY method significantly underestimated the slope of the vapour pressure line against laboratory measurements.

For the base case simulations the N-N/VP method was combined with the assumption of ideality. For the 5 cases exploring the sensitivity to predicted component volatility, combinations of the vapour pressure methods (MY and $\mathrm{N} / \mathrm{VP}$ ) with the boiling point methods (N, SB and JR) were used with the assumption of ideality (JR-N/VP, SB-N/VP, JR-MY, SB-MY and N-MY).

To analyse the impact of non-ideality, the base case combination (N-N/VP) was used with the UNIFAC model with updated parameters of Peng et al. (2001) to calculate activity coefficients of all components. This combination is hereafter referred to as N-N/VP-non-ideal. The updated parameters, used in previous atmospheric studies (Topping et al., 2005; Compernolle et al., 2009; Tong et al., 2008), have been shown to substantially improve predictions in systems which include the $\mathrm{OH}-\mathrm{COOH}$ subgroups. Other studies have focussed on improving interaction parameters for additional groups in addition to modifying the UNIFAC framework (e.g. Marcolli and Peter, 2005). There are few validation studies for such approaches, particularly for complex systems, and additional work is needed (Tong et al., 2008; Zuend et al., 2008) before they can be reliably applied.

\subsection{Framework for simulation initialisation}

To investigate the sensitivity of the model predictions to available estimation methods across as broad a composition space as possible, a methodology for the generation of the test initialisations of organic molecules of varying functionality has been constructed. 

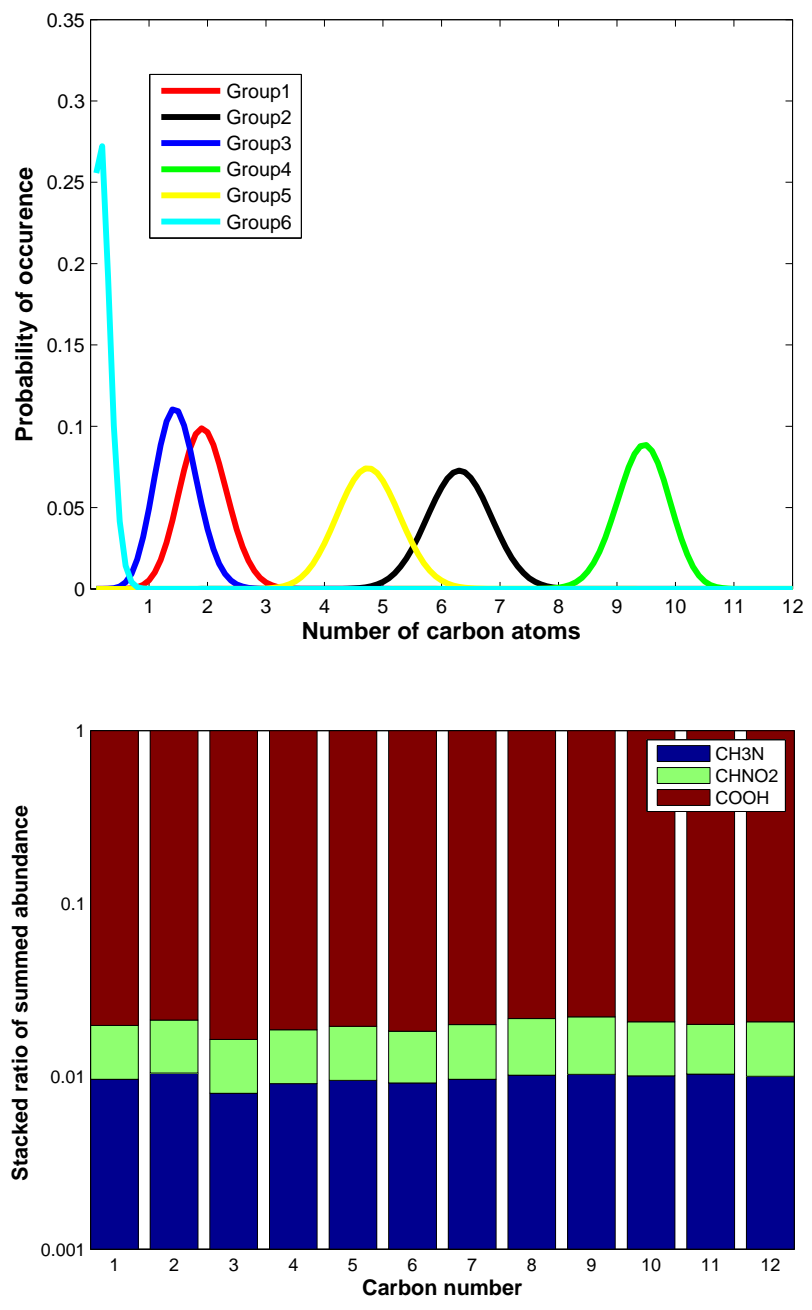

Fig. 1. (a) An illustration of a randomly-generated distribution of functional groups as a function of the carbon number. In each case, distributions of the 29 functional groups represented within the modified-UNIFAC model are generated (38 including hydrocarbon groups); only 6 are shown here for clarity; (b) the fractional distribution of three examplary functional groups across all 1000 initialisations, showing that the $\mathrm{COOH}$ group is present at roughly 100 times the mixing ratio of the $\mathrm{CH}_{3} \mathrm{~N}$ and $\mathrm{CHNO}_{2}$ groups.

A fully-randomised initialisation of the simulations has not been used. Instead, restrictions have been imposed during the construction of compound functionality and abundance to provide a large but finite number of simulations and a statistically significant distribution of results within a range of conditions representative of, or similar to, atmospheric conditions. This is to ensure that the sensitivity to the estimation methods is assessed on mixtures comprising components functionalised to a similar degree to those expected in the atmosphere.
In the current study only straight-chain aliphatic compounds from methane to $\mathrm{C}_{12}$ compounds are considered and therefore the organic compound carbon number solely determines the chain-length; an evaluation of the sensitivity to the predictive techniques for aromatic and cyclic compounds is considerably more complex and is presented in the separate third part of the study in the context of simulated components from a near-explicit VOC degradation mechanism. To generate a compound and prescribe its abundance, the following procedure was used:

(i) The carbon chain length was selected using a random number generator constrained between 2 and 12. The twister algorithm within the Matlab® software package is used. The sequence of numbers produced by this function, which has a period of $\frac{2^{19937-1}}{2}$ is determined by the internal state of the generator which is set based on the CPU clock.

(ii) Functionality was then assigned to the carbon backbone. 38 functional groups represented within the UNIFAC activity coefficient model were used, including the 9 hydrocarbon subgroups (Hansen et al., 1991). Each functional group was assigned a probability of occurrence on a carbon backbone, defined by a set of Gaussian probability density functions randomly generated for each initialisation. For example, for a chain length of 5 , the functional groups $\mathrm{COOH}, \mathrm{OH}, \mathrm{CH}_{2} \mathrm{CO}$ might have been assigned a probability of occurrence of 0.134 , $0.245,0.001$. For a chain length of 3 , the same groups may be assigned a different probability of occurrence of $0.346,0.102,0.091$. In generating these probabilities, weighted preference was given to oxygenated functional groups by multiplying the probability of occurrence of each group by 100 . This was used to increase the likelihood that such "preferred" groups would populate a given carbon chain, whilst still allowing "nonpreferred" functional groups to occur. This is with the aim to increase the $\mathrm{O}: \mathrm{C}$ ratio towards atmospheric levels (whilst not trying to exactly reproduce the VOC concentrations in the atmosphere). All main groups with their subgroups are shown in Table 1; Rows 1 to 7 list the "preferred" groups, 8 and 9 the hydrocarbon groups and 10 to 19 the other "non-preferred" groups. Figure 1a illustrates a representative hypothetical distribution for only 6 functional groups for clarity. Obviously the probability is only valid for integer values of carbon number; these being selected from the generated real number functions. For a given initialisation for simulations of mixtures comprising 2, 10, 100, 1000 and 10000 compounds, each compound is generated using the same set of probability density functions. Across the 1000 initialisations, this provides broadly uniform probabilities of occurrence of functional groups across all initialisations. An example of the normalised distribution 
of selected functional groups across all initialisations is shown in Fig. 1b illustrating that "two non-preferred" functional groups are present at roughly 100 times lower concentration than the "preferred" $\mathrm{COOH}$ group at all carbon numbers using the semi-randomly generated probabilities.

(iii) The initial guess for the total abundance of the generated compound is constrained such that the molar mixing ratio $(r)$ of a compound decreases linearly in logarithmic space with increasing carbon number. The gradient is defined by assuming the total mixing ratio of $\mathrm{C}_{1}$ compounds is approximated by mean methane value of $1776 \mathrm{nmolmol}^{-1}$ (ppbv) and a prescribed mixing ratio for each $\mathrm{C}_{12}$ compound of around $1 \mathrm{pmolmol}^{-1}$ (pptv) such that a mixing ratio in nmolmol ${ }^{-1}$ of a compound of carbon number $x$ is given by:

$$
r=\frac{1776}{(1776 / 0.001)^{\frac{x-1}{11}}}
$$

The logarithmic reduction is to ascribe a falloff in organic compound concentration to part per trillion levels for larger carbon number compounds, broadly in line with what is observed in the atmosphere. No exact rigorous representation of the atmospheric organic loading was sought.

(iv) The total "target" condensed organic mass loading is fixed at $10 \mu \mathrm{g} \mathrm{m}^{-3}$ for all partitioning calculations, at all ambient conditions, using the base choice of ideality with the N-N/VP vapour pressure prediction. This criterion is chosen to ensure that the sensitivities are not influenced by the availability of condensed mass. The condensed mass determines the relative contributions to the mass by components of different volatilities. A higher mass of material would lead to a higher relative contribution from more volatile compounds and conversely a lower mass of material would lead to a higher relative contribution from less volatile material. In order to achieve this, the total abundance of components must be varied for each initialisation. The total abundance of the generated compounds described in step (iii) above is adjusted iteratively to achieve this condensed mass whilst maintaining the gradient of the molar mixing ratio distribution line (i.e. such that there are fewer larger molecules in each simulation as would be expected in the atmosphere). To recap, in each base case partitioning simulation, be it for 2, 10, 100, 1000 or 10000 compounds, the base case (N-N/VP, ideality) predicted condensed mass is always $10 \mu \mathrm{g} \mathrm{m}^{-3}$.

Table 2 shows example initialisations satisfying the same random probability of functionality and carbon number. The initial total mixing ratio for each compound of a given carbon

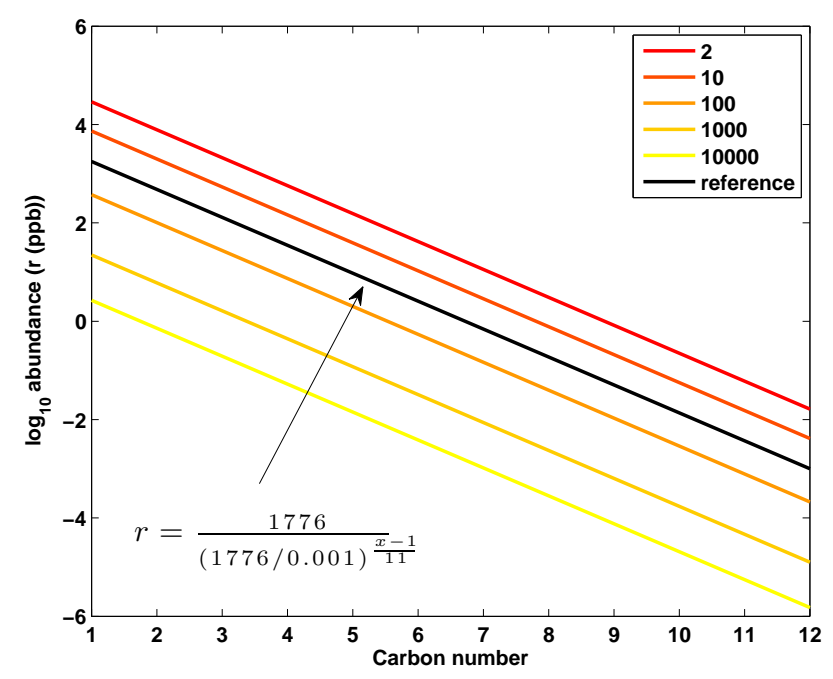

Fig. 2. The base case total mixing ratios of each compound of a given carbon number shown by the black line, demonstrating that the mixing ratios fall with carbon number $(x)$ logarithmically as defined by Eq. (4). The other lines show that the mixing ratios required to yield the "target" condensed loading of $10 \mu \mathrm{g} \mathrm{m}^{-3}$ at each level of complexity for any example initialisation run parallel to the base case "initial guess". 2 and 10 compound representations of this initialisation require that the mixing ratio is increased above the "initial guess" values and that the 100, 1000 and 10000 compound representations correspondingly require successive lowering of the mixing ratio.

number is the same base case value, as shown in the second column of the table. The third column of the table shows the scaling applied to the initialisation to yield the target mass of $10 \mu \mathrm{g} \mathrm{m}^{-3}$. For practical purposes, examplary initialisation listings of 100, 1000 and 10000 compounds are not shown, but the required total mixing ratios of each compound of a given carbon number are shown in Fig. 2, demonstrating that the mixing ratios fall with carbon number logarithmically, parallel to the base case "initial guess". It can be seen that 2 and 10 compound representations of this particular initialisation require that the mixing ratio is increased above the "initial guess" values in order to yield $10 \mu \mathrm{g} \mathrm{m}^{-3}$ of condensed SOA mass and that the 100, 1000 and 10000 compound representations correspondingly require successive lowering of the mixing ratio. It is an obvious generality that a larger number of compounds with any given probable functionality will each have a lower mixing ratio than fewer compounds satisfying the same functionality likelihood to yield the same condensed target mass on partitioning. For each initialisation, these molecular abundances are held constant and the vapour pressure method, or assumption of ideality, is changed within the partitioning simulation to yield a variation in the total condensed material. This forms the basis of analysis discussed in later sections. 
It is important to note that it is not the intention to present a sensitivity of absorptive partitioning calculations of the exact mixtures of compounds found in the atmosphere; only to assess method sensitivity in broadly the correct atmospheric regime. It should further be noted that the discussions and conclusions will be drawn from results of absorptive partitioning simulations of mixtures of straight-chain aliphatic compounds with no branched chain, aromatic or cyclic compounds representative of biogenic compounds. For technical reasons, this is an enormously more complex undertaking and is the subject of a separate manuscript as indicated. It is also clear from Table 1 that the functionality represented in the Hansen et al. (1991) matrix for UNIFAC interactions cannot represent all the aerosol functional groups observed or predicted to exist in the atmosphere and there is no reason to suspect that each of the "preferred" or "non-preferred" functional groups will be equally probable in the atmosphere. Notable omissions are nitrate, sulphate, peroxide, peroxyacid and anhydride functional groups. The Hansen et al. (1991) matrix represents the most comprehensive UNIFAC group representation so the sensitivities were carried out to the most comprehensive functionality accessible to the predictive techniques under conditions more representative of the atmosphere than the conditions under which the techniques were developed. This is the sole purpose of the paper. The third paper in this series evaluates sensitivities to components generated using a VOC degradation model and a technique to parse the molecular structures and map the predicted functionality onto the UNIFAC groups is described therein, along with the treatment of branched chain, aromatic and cyclic compounds.

\subsection{Calculation protocol}

As stated when describing the constraints on the component mixing ratio in Sect. 2.3 above, the target mass using the base model configuration was $10 \mu \mathrm{g} \mathrm{m}^{-3}$. Ambient atmospheric condensed organic loadings can range from below 0.1 to greater than $100 \mathrm{\mu g} \mathrm{m}^{-3}$ depending on environment and after Eq. (2), it can readily be seen that the partitioning of semivolatile components depends on the total condensed mass, $C_{\mathrm{OA}}$. The impacts of $C_{\mathrm{OA}}$ on the distribution of components of varying volatility between vapour and condensed phase has been widely investigated (see e.g. Donahue et al., 2006) and the target mass will affect the absolute values in the results to some degree. This could be the focus of further work using randomised initialisations and is performed as part of the sensitivity analysis using the near explicit mechanism in part 3 of this series of publications, but it is not expected to greatly impact on the relative sensitivities and is not investigated here. Using the base-case N-N/VP method assuming ideality, for each of the 1000 functionality sets at each complexity of representation of the mixture, partitioning calculations were carried out varying the absolute total component loading until the target mass was achieved. Each calculation was conducted at three temperatures (273, 298 and $313 \mathrm{~K})$ spanning a reasonable tropospheric range and four relative humidities $(0,60,80$ and 90\%). Simulations for each functionality distribution, using each complexity of representation under each set of conditions with the appropriately adjusted total abundance was then repeated for each combination of predictive techniques. Owing to the large number of simulations, all the techniques and model configurations were automated. The calculations were then repeated using each of the estimation methods with the same total mixing ratios for all initialisations.

Although the chosen conditions are relatively arbitrary (and the participation of water in absorptive partitioning is quite contentious, see discussion in Sect. 3.1 below), an exhaustive investigation is computationally prohibitive and the selected conditions adequately serve to illustrate the sensitivities, notwithstanding the absence of real atmospheric constraint on the organic composition. The investigation could further be extended almost infinitely to consider condensation onto pre-existing organic mixtures of primary origin (or otherwise of lower volatility and varied functionality, such as components formed from significant atmospheric condensed phase processing) or to consider the presence of inorganic components. We will necessarily limit the current investigation to the conditions stated here, noting that such extensions may serve to either increase or decrease the sensitivity to a hitherto unknown degree.

\subsection{Evaluation metrics}

Conventionally, the total condensed organic mass loading has been the most widely reported metric for model comparison, largely because it is the one most readily accessible to ambient measurement. Recently a much broader range of comparators has emerged from field and laboratory studies and it is a more challenging test of model skill for predictions to be compared with the broadest set of available metrics. The partitioning sensitivities have therefore been evaluated using:

(i) total mass loading and the distribution of (ii) component mass loadings (for comparison with e.g. mass spectral parent ion fragment distribution and molecular identification, see e.g. Hamilton et al., 2008), iii) component volatility distribution for comparison with thermodenuder characterisations (see e.g Huffman et al., 2009), (iv) O:C ratio for comparison with online higher resolution mass spectra from recently developed instrumentation (e.g. DeCarlo et al., 2006) and molar mass (from e.g. osmometry or size-exclusion chromatography) (Kiss et al., 2003) and illustrated using (v) component functionality. The current status of organic composition related to all these metrics is discussed in detail in Hallquist et al. (2009). 
Table 1. Functional groups used in the initialisations and hence throughout the sensitivity simulations.

\begin{tabular}{|c|c|c|c|c|c|c|}
\hline 1 & alcohol & $\mathrm{OH}$ & & & & \\
\hline 2 & carbonyl (CH2CO) & $\mathrm{CH}_{3} \mathrm{CO}$ & $\mathrm{CH}_{2} \mathrm{CO}$ & & & \\
\hline 3 & ether-1 (CHO) & $\mathrm{CHO}$ & & & & \\
\hline 4 & acetate $(\mathrm{CCOO})$ & $\mathrm{CH}_{3} \mathrm{COO}$ & $\mathrm{CH}_{2} \mathrm{COO}$ & & & \\
\hline 5 & formate (HCOO) & $\mathrm{HCOO}$ & & & & \\
\hline 6 & ether-2 (CH2O) & $\mathrm{CH}_{2} \mathrm{O}$ & $\mathrm{CH}_{3} \mathrm{O}$ & & & \\
\hline 7 & carboxyl $(\mathrm{COOH})$ & $\mathrm{COOH}$ & & & & \\
\hline 8 & alkane $(\mathrm{CH} 2)$ & $\mathrm{CH}_{3}$ & $\mathrm{CH}_{2}$ & $\mathrm{CH}$ & $\mathrm{C}$ & \\
\hline 9 & $\alpha$-olefin $(\mathrm{C}=\mathrm{C})$ & $\mathrm{CH}_{2}=\mathrm{CH}$ & $\mathrm{CH}=\mathrm{CH}$ & $\mathrm{CH}_{2}=\mathrm{C}$ & $\mathrm{CH}=\mathrm{C}$ & $\mathrm{C}=\mathrm{C}$ \\
\hline 10 & primary amine (CNH2) & $\mathrm{CH}_{3} \mathrm{NH}_{2}$ & $\mathrm{CH}_{2} \mathrm{NH}_{2}$ & $\mathrm{CHNH}_{2}$ & & \\
\hline 11 & secondary amine $(\mathrm{CNH})$ & $\mathrm{CH}_{3} \mathrm{NH}$ & $\mathrm{CH}_{2} \mathrm{NH}$ & $\mathrm{CHNH}$ & & \\
\hline 12 & tertiary amine $((\mathrm{C}) 3 \mathrm{~N})$ & $\mathrm{CH}_{3} \mathrm{~N}$ & $\mathrm{CH}_{2} \mathrm{~N}$ & & & \\
\hline 13 & $(\mathrm{CCN})$ & $\mathrm{CH}_{3} \mathrm{CN}$ & $\mathrm{CH}_{2} \mathrm{CN}$ & & & \\
\hline 14 & $(\mathrm{CCl})$ & $\mathrm{CH}_{2} \mathrm{Cl}$ & $\mathrm{CHCl}$ & & & \\
\hline 15 & $(\mathrm{CCl} 2)$ & $\mathrm{CH}_{2} \mathrm{Cl}_{2}$ & $\mathrm{CHCl}_{2}$ & & & \\
\hline 16 & $(\mathrm{CCl} 3)$ & $\mathrm{CHCl}_{3}$ & & & & \\
\hline 17 & $(\mathrm{CNO} 2)$ & $\mathrm{CH}_{3} \mathrm{NO}_{2}$ & $\mathrm{CH}_{2} \mathrm{NO}_{2}$ & & & \\
\hline 18 & iodo (I) & I & & & & \\
\hline 19 & bromo $(\mathrm{Br})$ & $\mathrm{Br}$ & & & & \\
\hline
\end{tabular}

Table 2. Example initialisations satisfying the same random probability of functionality and carbon number. These mixing ratios are illustrated in Fig. 2 in addition to those for each component in the 100, 1000 and 10000 compound representations of the same initialisation.

\begin{tabular}{|c|c|c|c|}
\hline Functional Groups & Carbon Number & $\begin{array}{c}\text { "First Guess" } \\
\text { Mixing Ratio } \\
\text { nmolmol }{ }^{-1}\end{array}$ & $\begin{array}{r}\text { Converged } \\
\text { Mixing Ratio } \\
\mathrm{nmolmol}^{-1}\end{array}$ \\
\hline \multicolumn{4}{|l|}{2 compounds } \\
\hline $\mathrm{CH}_{3} \mathrm{CH}_{2} \mathrm{CO} \mathrm{CH} \mathrm{CH}_{2} \mathrm{COOH}$ & 5 & 9.4776 & 155.51135 \\
\hline $\begin{array}{l}\mathrm{CH}_{3} \mathrm{OH} \mathrm{CH}_{3} \mathrm{CH}_{2} \mathrm{COO} \mathrm{C}=\mathrm{C} \\
10 \text { compounds }\end{array}$ & 6 & 2.5621 & 42.036922 \\
\hline $\mathrm{CH}_{3} \mathrm{CH}=\mathrm{CH} \mathrm{CH} \mathrm{CH}_{2} \mathrm{OH} \mathrm{COOH} \mathrm{CH} \mathrm{NO}_{2}$ & 7 & 0.69262 & 2.937796 \\
\hline $\mathrm{CHO} \mathrm{CH}_{3} \mathrm{OH} \mathrm{C}=\mathrm{C}$ & 4 & 35.0590 & 148.73572 \\
\hline $\mathrm{CH} \mathrm{CH}=\mathrm{C} \mathrm{CH}_{2} \mathrm{CO} \mathrm{COOH} \mathrm{COOH} \mathrm{CH} \mathrm{NO}_{2}$ & 8 & 0.18724 & 0.7941281 \\
\hline $\mathrm{CH}_{2} \mathrm{CHO} \mathrm{CH}_{2} \mathrm{CO}$ & 4 & 35.0590 & 148.73572 \\
\hline $\mathrm{CH}_{3} \mathrm{CH}_{2}=\mathrm{C} \mathrm{OH} \mathrm{COOH} \mathrm{CH} \mathrm{CH}_{2} \mathrm{CN}$ & 6 & 2.5621 & 10.868082 \\
\hline $\mathrm{CH}_{3} \mathrm{CH}_{2} \mathrm{CHO}$ & 4 & 129.688 & 550.23278 \\
\hline $\mathrm{C}=\mathrm{C} \mathrm{COOH} \mathrm{CH} \mathrm{CH}_{2} \mathrm{O} \mathrm{CH}_{2} \mathrm{~N}$ & 6 & 2.5621 & 10.868082 \\
\hline $\mathrm{CH}_{3} \mathrm{COO} \mathrm{CH} \mathrm{CH}_{2}$ & 3 & 129.688 & 550.23278 \\
\hline 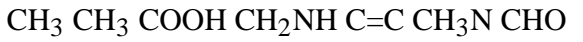 & 8 & 0.18724 & 0.7941281 \\
\hline $\mathrm{CH} \mathrm{OH} \mathrm{CH} \mathrm{CH}_{2} \mathrm{OHO}$ & 3 & 129.688 & 550.23278 \\
\hline
\end{tabular}

3 Results: model sensitivity to predicted properties and the complexity of the representation of the organic aerosol fraction

\subsection{Predicted condensed organic mass}

In general, across all sets of functionality, it was found that the predicted mass is less sensitive to the assumption of ideality than to the accuracy of the vapour pressure prediction. This is clearly illustrated in Fig. 3, which presents the sensitivity of total condensed mass for a single functionality distribution to all changes in the vapour pressure predictive technique (green box and whiskers) and the inclusion of nonideality (red box and whiskers) compared with the base case for simulations across all conditions at each level of complexity. Note the logarithmic scale of the mass axis. The first box and whisker bar of each pair represents the variability in predicted mass from the simulations from all models at all non-zero RH values, whereas the right hand bar of each pair shows the range of variability from only the dry simulations. Under "wet" conditions, the median value of mass predicted from all methods using non-base vapour pressure variant models (number of models used $=n=45$ ) is always greater 


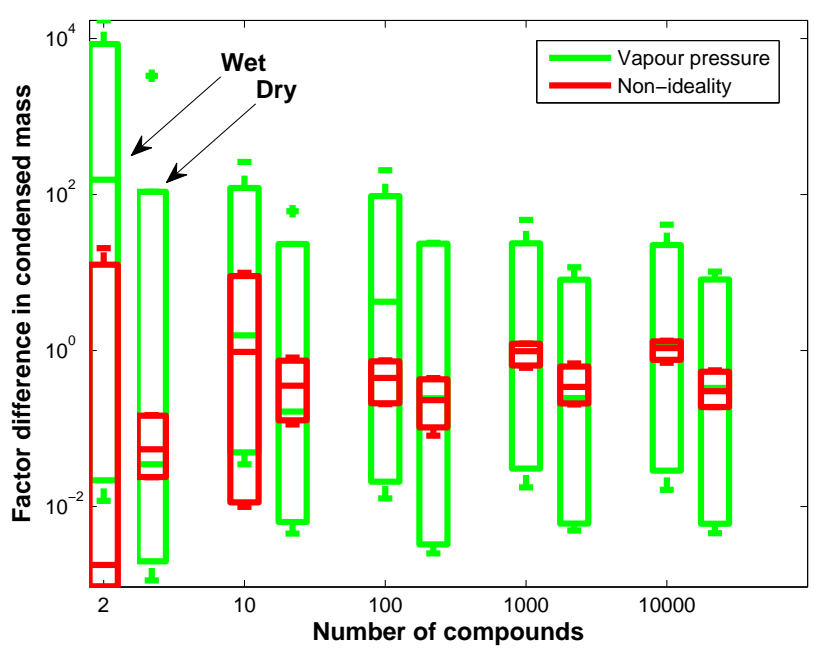

Fig. 3. An example illustration of the sensitivity of predicted total condensed organic mass across all conditions to the differences in vapour pressure predictive technique in the partitioning model (green bars, $n=45$ ) and the inclusion of non-ideality (red bars, $n=9)$. The left-hand bar in each pair encompasses all property prediction variants, all $\mathrm{T}$ - and $\mathrm{RH}$-values.

than the base mass prediction, with a small minority of simulations producing less mass than those using the N-N/VP base model. Under dry conditions using the non-base vapour pressure models $(n=15)$, with no absorptive mass provided by condensed water, the median value drops slightly below the base case mass with partitioning. The reason for the difference in behaviour is illustrated in Fig. 4 where the mass loading predicted using each of the vapour pressure estimation technique variants in the partitioning model is illustrated for the mixtures as in Fig. 3. The systematic overprediction in mass resulting from use of the JR $T_{\mathrm{b}}$ technique with its underprediction in volatility can be seen in the right hand panels where, for "wet" conditions (green bars) a greater overprediction in mass is shown than for dry conditions (blue points) as a result of the presence of liquid water as an absorbing mass (note that only three dry cases are available at each degree of simplification of a given functionality set for each model, therefore each point is plotted rather than attempting to plot statistical variability). The other techniques can be seen to predict substantially lower mass than the techniques using the JR $T_{\mathrm{b}}$ method and indeed, reduced mass on average when compared with the base case N-N/VP method. In all cases, absorptive partitioning shows comparable sensitivity in predicted mass to the varying methods under dry and "wet" conditions. Furthermore, the variation of the model leads to greater median mass underprediction if the mass is underpredicted with respect to the base case or lower mass overprediction for the JR-based techniques.
Whilst Fig. 4 only illustrates the dependence assuming ideality, the red bars in Fig. 3 show that non-ideality, as captured by the UNIFAC model, leads in general to an underprediction of mass. Possibly surprisingly, under "wet" conditions, the median mass prediction is closer to that predicted by the base case than under dry conditions for all levels of complexity of mixture representation other than the simplest 2 component cases. This indicates on average that there is a lower degree of predicted non-ideality in cases where water is present. It should be noted that, whilst a strong predicted dependence of condensed mass on RH has been presented in Barley et al. (2009) and Hallquist et al. (2009) and RH dependence has been discussed in Seinfeld et al. (2001) and Pankow and Chang (2008), the degree to which condensed water acts as an effective absorptive mass is unclear.

Both Figs. 3 and 4 also illustrate that the sensitivity tends to reduce on increasing complexity from the simplest representations of the partitioning compounds. Although both figures show only the results from one randomly generated functionality distribution, these are typical and both results were found to be the general case for over 1000 randomly generated organic only or organic/water mixtures (see Fig. 5). The condensed mass can vary by a factor of $10^{4}$ for simple mixtures with two compounds using widely used vapour pressure predictive techniques. For the same mixture, the condensed mass can be almost three orders of magnitude lower when including activity coefficients. By this most coarse metric, the potential for very high uncertainty is highlighted when using both reduced and high complexity representations of organic aerosol composition, particularly related to the choice of vapour pressure predictive technique. The relatively low sensitivity to the inclusion of the particular activity coefficient model used here for high complexity mixtures is another general result, suggesting that nonideality in very complex mixtures plays a more minor role, probably resulting from the very low mole fraction of each individual component. It must be restated that such considerations ignore phase separation or the presence of inorganic components, both of which may increase the impacts of nonideality.

To demonstrate the generality of the results, Fig. 5 shows the probability distribution functions of the sensitivity of the predicted total condensed organic mass across all conditions to the differences in vapour pressure predictive technique and the inclusion of non-ideality. This figure reinforces the typical results observed in Figs. 3 and 4 and described above and shows that the sensitivities can be both smaller and very much larger than the single example depending on the distribution of functionality of the compounds present. It can be seen that there is a slight overall bias towards overprediction of total mass when varying the vapour pressure predictive technique from the base method of both boiling point and vapour pressure estimation, N-N/VP. In contrast, there is a slight overall bias towards the underprediction of lower total mass by the inclusion of non-ideality using the UNIFAC 

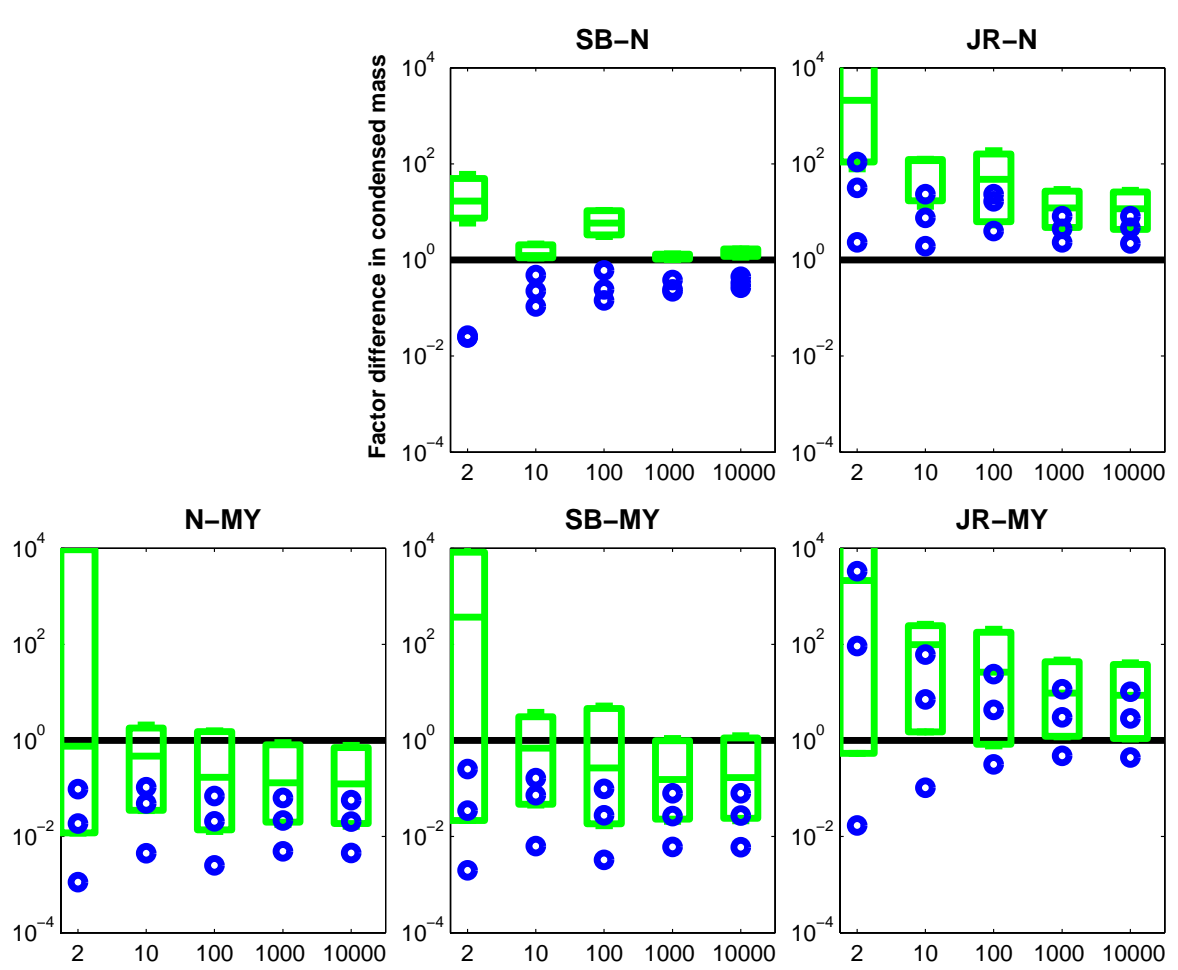

Fig. 4. Sensitivities of predicted total organic mass for an example functionality distribution across changing temperatures for wet (green bars, $n=9$ ) and dry (blue symbols, $n=3$ ) conditions using the partitioning model with each of the vapour pressure predictive techniques.

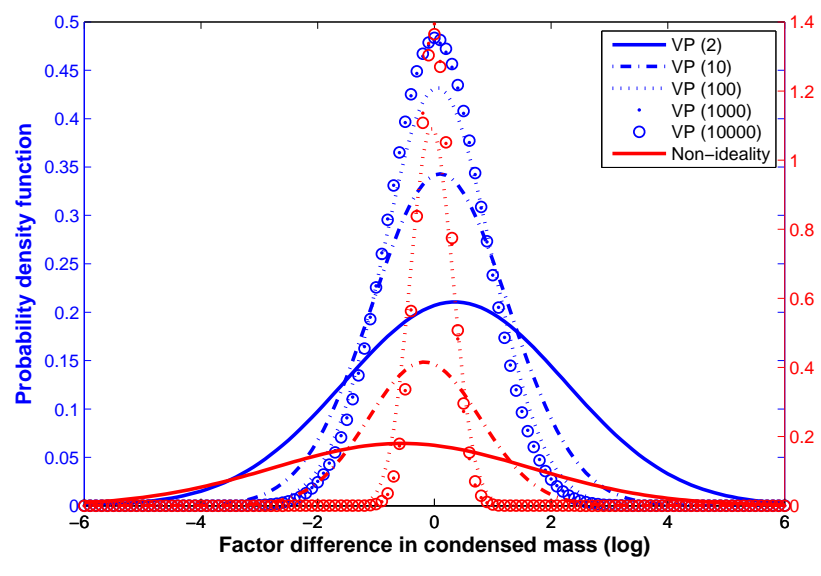

Fig. 5. Distribution of sensitivities of predicted total organic mass to change in vapour pressure technique and the inclusion of nonideality across all 1000 functionality distributions. The bracketed numbers in the legend refer to the number of partitioning compounds defining the complexity of the representation of the SOA.

method described in Sect. 2.2 above. The distribution of predictions has an increasingly broader spread with increasing simplicity of system representation - i.e. much greater underor over-prediction is possible when a low complexity representation of the organic components is used. Furthermore, the deviations tend towards a similar finite value with increased complexity, such that even with a very large number of components there is a significant sensitivity of the predicted mass to the techniques employed.

\subsection{Predicted volatility of the condensed mass}

Donahue et al. (2006) reformulated the absorptive partitioning model to define an effective saturation concentration, $C_{i}^{*}$ of each component, that would be identical to the inverse of $K_{p, i}$ for each component were they all to be of the same molar mass. The $C_{i}^{*}$ value may then be used as a direct measure of the volatility, with lower $C_{i}^{*}$ components being more liable to be in the particulate material. Figure 6 shows an example of the distribution of the compounds binned by their volatility in a simulation of a 10000 compound representation of a single functionality distribution predicted at $T=298.15 \mathrm{~K}$ and $\mathrm{RH}=80 \%$ using each of the predictive methods. It can be seen that there is a very large, and somewhat predictable, sensitivity to the vapour pressure predictive technique employed, with components moving between $C_{i}^{*}$ bins leading to very different volatility distributions. The reason for the predictability of the differences in the volatility distributions for the same initialisation but using different means of predicting the vapour pressure (i.e. volatility) is that the same components will be present in each case, but the volatility predicted will differ using each method. 

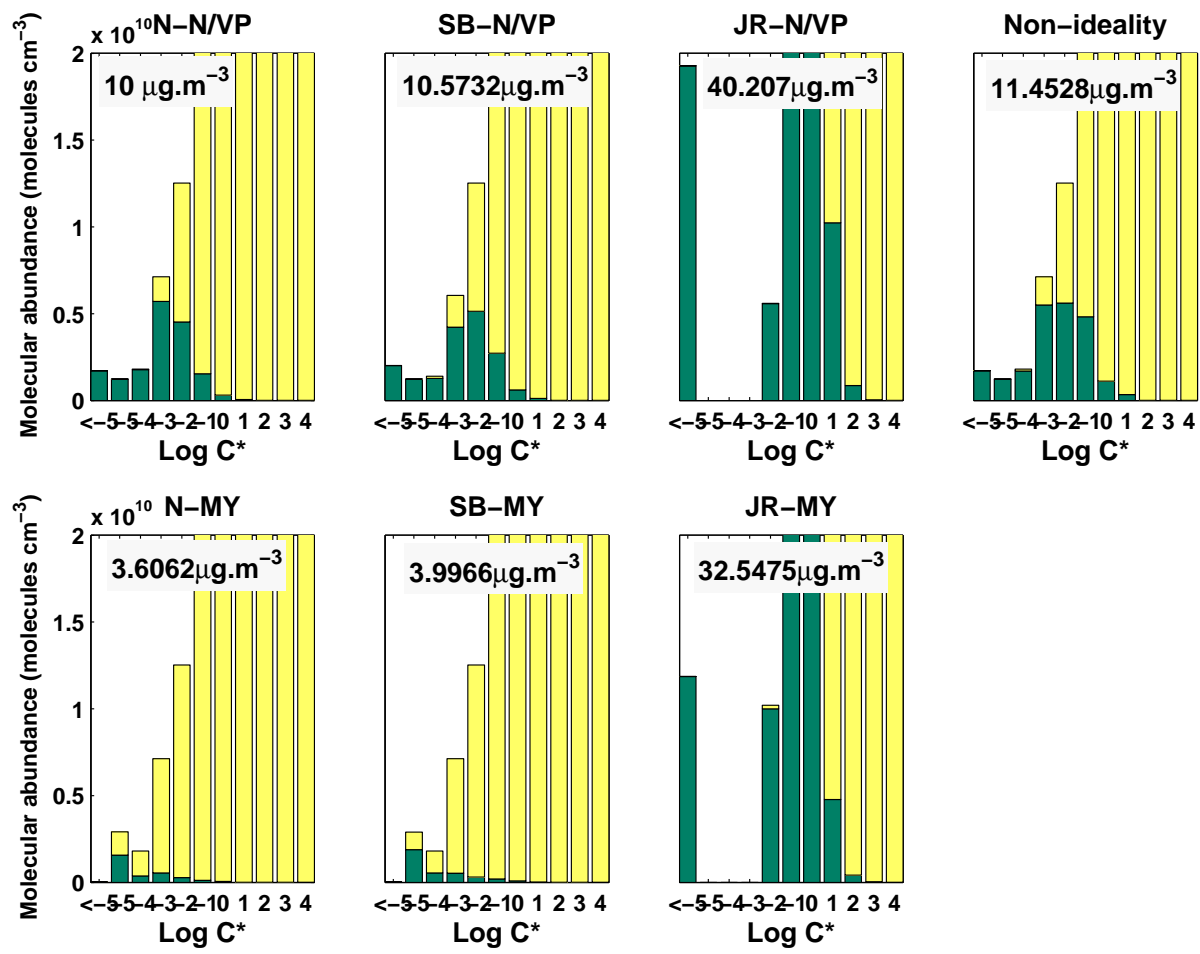

Fig. 6. Predicted binned component volatility for a 10000 compound representation of one example functionality distribution set. The abscissa is the base 10 logarithm of the saturation concentration of the components in the respective volatility bin. The green bars correspond to the particulate and the yellow to the vapour phase. The total condensed mass is indicated on each panel.

Unless any differences between the vapour pressure estimation techniques were completely systematic and independent of functionality, then the distribution of predicted components will be different. It is demonstrated in Sect. 3.3 below, that the differences in predictions from different estimation techniques are not systematic in terms of molar mass or O:C ratio and and components will be unlikely to shift between $C_{i}^{*}$ bins in a systematic way.

By comparison, the predicted sensitivity of the volatility distribution to non-ideality is seen to be very much lower. Figure $7 \mathrm{a}$ and $\mathrm{b}$ show the sensitivity of the volatility distribution to changes in predictive technique across all 1000 functionality sets for the most simple (2 component) and most complex (10 000 component) representations of the functionality respectively. The red bars show the range of volatility of the components in the base case. The height of the bar represents the percentage contribution to the total condensed SOA mass. The green and blue box and whiskers both show the relative change in the percentage contribution to the total SOA mass from each volatility bin referenced to the base case using all the different predictive techniques; the blue symbols do not consider variations resulting from use of the JR $T_{\mathrm{b}}$ technique whereas the green do. Figure 7a shows that, when only two compounds are used to represent the functionality distribution, the base case volatility bins that they fall into will range widely depending on the initial functionality. When the vapour pressure estimation techniques are varied or non-ideality considered, the volatility distributions show a broad scatter such that no statistical pattern is observed. That is, the distribution of component volatility is so sensitive to the methods employed that they must be considered unreliable when representing the organic functionality by only two components. In contrast, when representing the same 1000 functionality initialisations by 10000 components in each mixture, it can be seen from Fig. $7 \mathrm{~b}$ that the base case volatility distribution (as represented by the red bars), may be considered broadly reasonable and comparable to the top left panel in Fig. 6. Therefore it can be seen that the sensitivity shown in Fig. 6 is representative of all the 1000 semi-random functionality distributions. The complex representation (Fig. 7b) exhibits much lower sensitivity to the variation in estimation technique than the simple representation (Fig. 7a) in that a statistical range can be described by the blue and green box and whiskers. However, the sensitivity is still very large. The volatility distribution shows that components frequently move in the decadal volatility bin distribution. The green points, including predictions using methods that employ the JR $T_{\mathrm{b}}$ technique (which lead to a systematically tendency to underpredict vapour pressure) appear to show systematic increases in the fractional contribution 


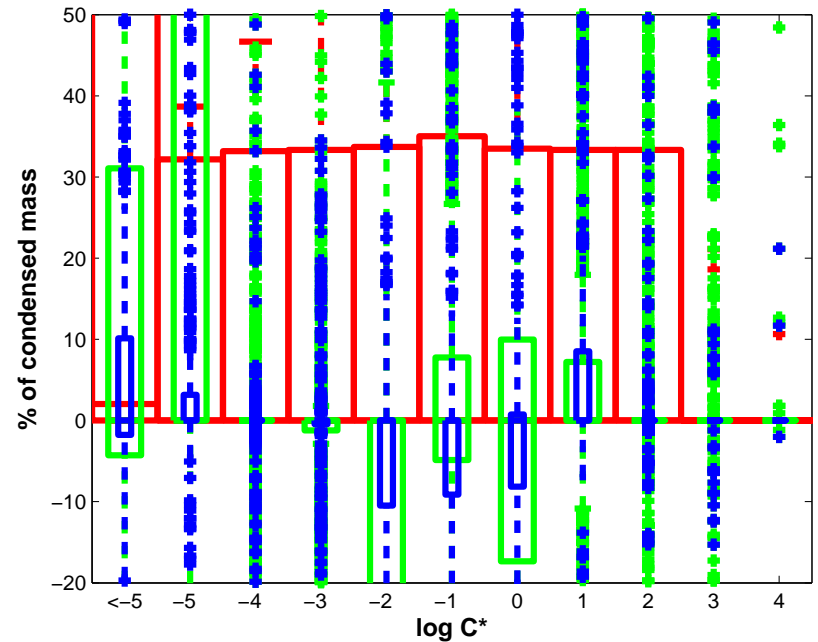

(a) 2 components

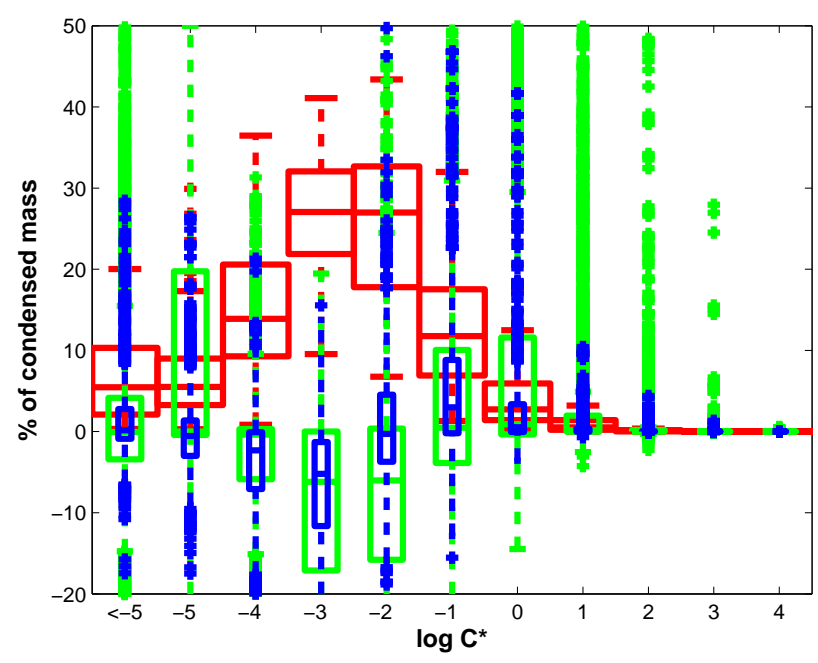

(b) 10000 components

Fig. 7. Sensitivity of the volatility distribution, in terms of the variability in $\%$ contribution to total condensed mass, to changes in predictive technique across all 1000 functionality sets. The red bars show the range of volatility of the components in the base case as a percentage of the condensed SOA mass. The green and blue box and whiskers both show relative change in the percentage contribution to the total SOA mass from each bin referenced to the base case; the blue symbols do not consider variations resulting from use of the JR $T_{\mathrm{b}}$ technique whereas the green do. The choice of techniques shifts the distribution of condensed material in different volatility bins, with a smaller systematic difference to the base case when the JR technique is not used. Note the large bias towards components in the $\log \left(C_{i}^{*}\right)=-5$ bin when JR is used.

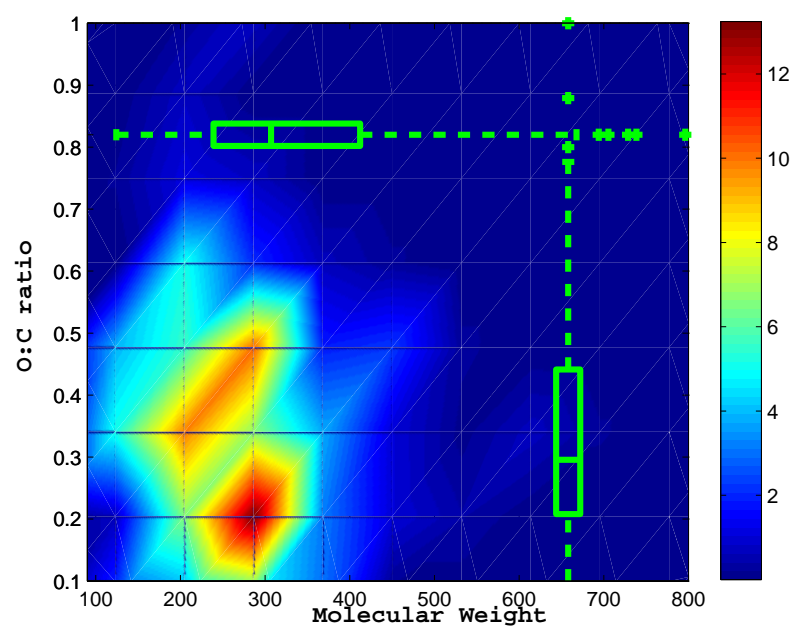

(a) Representing the functionality distributions by 2 compounds

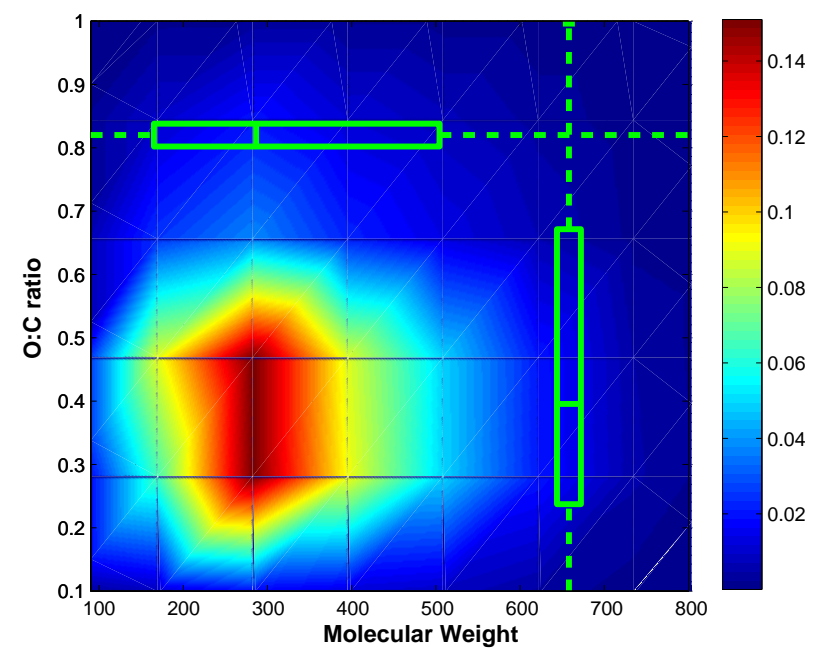

(b) Representing the functionality distributions by 1000 compounds

Fig. 8. Predicted frequency distribution of normalised massweighted average O:C ratio and $M_{\mathrm{W}}$ for each of 1000 simulations using the base N-N/VP method in the partitioning model, with units of normalised frequency in each bin of 0.05 in O:C and $50 \mathrm{~g} \mathrm{Mol}^{-1}$ in $M_{\mathrm{w}}$

from the components in the low volatility $\log \left(C_{i}^{*}\right)=-5$ bin whereas the non-base case methods that do not employ the JR $T_{\mathrm{b}}$ technique (blue points) show little systematic difference.

\subsection{Predicted condensed component molar mass and O:C ratio distribution}

Frequently $\mathrm{O}: \mathrm{C}$ ratio and molar mass are becoming more widely available from a variety of analytical techniques. Across the 1000 initialisations, it is found that the predicted component mass variation from each method is not uniform in terms of the molar mass, $M_{\mathrm{W}}$, or oxygen to carbon 
$(\mathrm{O}: \mathrm{C})$ ratio. Figure $8 \mathrm{a}$ and $\mathrm{b}$ show the normalised mass weighted frequency distribution of the component properties averaged across 2, and 1000 components, respectively used to represent each of 1000 functionality distributions across all temperatures and RH using the base N-N/VP estimation method in the partitioning model. The average $\mathrm{O}: \mathrm{C}$ ratios and $M_{\mathrm{W}} \mathrm{s}$ are binned with a resolution of 0.05 in O:C and 50 in $M_{\mathrm{w}}$. It can be seen that the average properties of the two component representations fall in two clusters, one with higher $\mathrm{O}: \mathrm{C}$ ratio and lower molar mass than the second; whereas the average properties of the 1000 component representations form a continuous distribution across all 1000 simulations. The boxes and whiskers show the statistical distribution of these properties, with the median value falling at the central "hotspot" of the frequency contour in the high complexity panel (b) and between the two hotspots in the two component panel (a). In contrast to the averages across a high number of simulations, the panels in Fig. 9 show the results from a single example simulation of a 10000 compound representation of a single functionality set. The scale is the logarithm of the condensed mass loading in each bin with the same bin resolution as Fig. 8. Figure 9a shows that the distribution of these properties across all compounds using the base case method is broadly within a range representative of the entire average of all 1000 functionalities seen in Fig. 8. Figure $9 \mathrm{~b}$ shows the distribution of the properties using the JR-N/VP estimation method on the same scale. It is evident that the total predicted mass is increased (as has already been shown in Fig. 3). Figure 9c shows the logarithm of the differences in the mass distributions. Clearly the differences are not systematic and the discrepancies in the predicted loadings vary significantly as a function of both molar mass and O:C ratio. It is evident that the choice of estimation methods in absorptive partitioning predictions will substantially impact on the identification or selection of semivolatile components and their properties in the organic fraction of particulate material. Figure 10 shows the distribution of the average O:C ratios and $M_{\mathrm{w}} \mathrm{s}$ of the predicted condensed mass across all conditions and 1000 initialisations, with the box-and-whiskers showing the median, interquartile and 95\% ranges for each combination of estimation techniques; the cross shows the location of the average composition from the base-case technique and the coloured open symbols show the average predicted using each of the different techniques. It can be seen that on average the $M_{\mathrm{w}}$ of secondary organic mass is lower using techniques employing the JR method. This is consistent with the method predicting higher $T_{\mathrm{b}}$ and hence molecules of lower molar mass becoming more condensable than predicted using more accurate methods. It can be seen that the correction applied to the JR in developing the SB technique leads to its use in combination with the $\mathrm{N} p^{0}$ technique yielding a similar average O:C ratio and $M_{\mathrm{w}}$ to the base case method. Whilst the methods employing the MY $p^{0}$ prediction method also predict an average $M_{\mathrm{w}}$ lower than the base case, the average O:C ra- tio is substantially higher, indicating that a higher degree of oxygenation is required on average across all initialisations using these methods for the molecules to be condensable.

\section{Discussion, conclusions and future work}

The functionality of the condensed phase differs markedly depending on the predictive techniques employed in the partitioning model and this leads to the substantial differences in total mass, component and average volatility, O:C ratio and molar mass illustrated above. Figure 11 shows an example from one randomly generated set of input concentrations. The predictions of condensed organic components are extremely dependent on the employment of the appropriate vapour pressure and activity coefficient predictive technique. As may be expected, it can clearly be seen that the differences in the functionality of condensed organic components using the different predictive techniques is reflected in the variation in distribution of $\mathrm{OC}$ ratio, molar mass and volatility. Whilst absorptive partitioning will undoubtedly be incapable of explaining all features of secondary organic aerosol formation, it can be used to provide an indication of the equilibrium distribution of functionality that may be expected in the absence of heterogeneous or condensed phase reaction. Any comparison of such predictions with laboratory simulations in well-defined conditions or with atmospheric samples may allow the extent to which equilibrium absorptive partitioning determines organic functionality to be assessed. It is evident from Fig. 11 that the randomly-generated initialisations used to evaluate the sensitivity do not exactly represent the distribution of components found in the atmosphere, but it should be noted that this was not a primary criterion of the investigation. This was to evaluate property estimation techniques that have been used in the atmosphere in an absorptive partitioning framework under conditions and for components that are more representative of the atmosphere than those used to develop the techniques.

Whilst the impacts of the techniques for prediction of nonideality are demonstrated to be lower than of vapour pressure, the sensitivities presented have hitherto ignored the presence of inorganic components. In real ambient mixed organic/inorganic aerosol, the situation will be further complicated and the role of non-ideality may be substantially larger. Figure 12 demonstrates the increase in the sensitivity of predicted condensed mass resulting from inclusion of inorganic components (in this case $\mathrm{NaCl}$ ) for a single example functionality distribution by incorporation of the AIOMFAC model (Zuend et al., 2008) in the absorptive partitioning framework for the same range of conditions as in Fig. 2. It can be seen that the predicted mass sensitivity to non-ideality when including inorganic components assuming internal mixing is comparable in magnitude to consideration of organic component non-ideality only (equivalent to organic and inorganic components being 


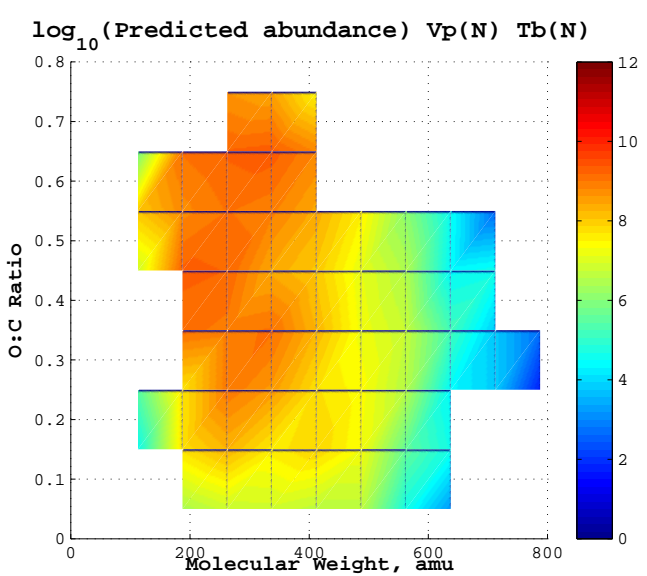

(a) Base configuration

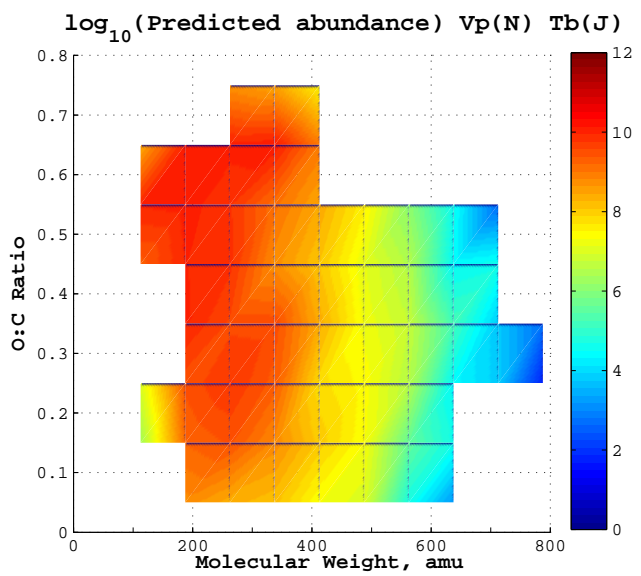

(b) Base configuration with $T_{b}$ prediction uses the Joback method

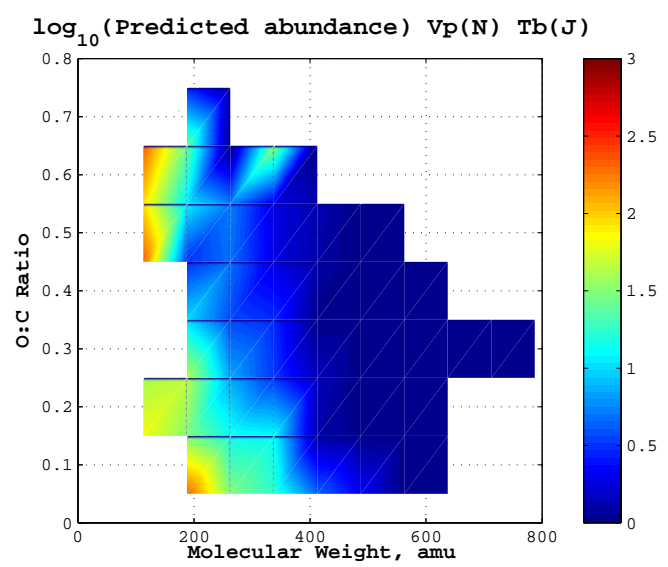

(c) Difference between a) and b)

Fig. 9. Predicted condensed organic component mass plotted as a function of molar mass and $\mathrm{O}: \mathrm{C}$ ratio from a single initialisation. When using the JR technique, it can be seen that the variation in component mass from the base prediction is not uniformly distributed.

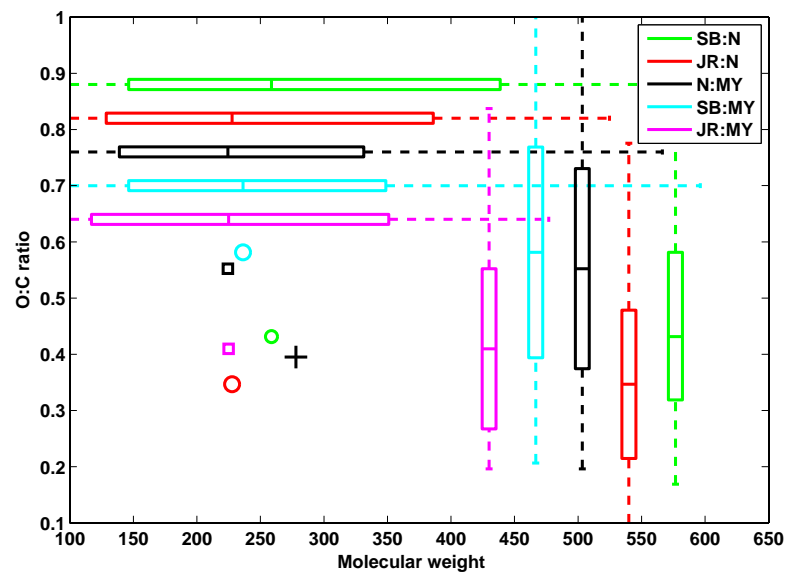

Fig. 10. The distribution of the average O:C ratios and $M_{\mathrm{w}} \mathrm{s}$ of the predicted condensed mass across all conditions and 1000 initialisations, with the box-and-whiskers showing the median, interquartile and $95 \%$ ranges for each combination of estimation techniques; the cross indicates the average composition from the base-case technique and the coloured open symbols show the average predicted using the other technique. On average the $M_{\mathrm{W}}$ of secondary organic mass is lower using techniques using JR, consistent with overprediction of $T_{\mathrm{b}}$ and lower molar mass compounds becoming too condensable. The correction applied to the JR yielding the SB technique leads to more similar average $\mathrm{O}: \mathrm{C}$ ratio and $M_{\mathrm{W}}$ to the base case method. The methods employing MY also predict average $M_{\mathrm{W}}$ lower than the base case but higher average O:C ratio. A higher degree of oxygenation is therefore required on average across all initialisations using these methods for the molecules to be sufficiently involatile to condense.

externally-mixed). However, the absolute loadings may be substantially different (in this case, mostly greater when internally-mixed). Development and evaluation of mixed inorganic/organic models for atmospheric applications is incomplete and the further laboratory studies are required to cover the range of atmospherically-relevant functionality (see e.g. Tong et al., 2008). In such systems (indeed, even in systems with both polar and non-polar organic components or simply organic components plus water), it is likely that phase separation may occur (Erdakos and Pankow, 2004). In a recent study, it has been shown that for a particular moist multicomponent system, up to $30 \%$ overestimation of mass can result from ignoring non-ideality and liquid-liquid phase separation (Zuend et al., 2010). This should be the subject of continued investigation. However, it must be noted that an aerosol is a dispersed system and phase separation naturally occurs by virtue of the numerous phase boundaries present, such that partitioning calculations of component mass are simply averages across all particles. Whilst the effect of non-ideality will be further complicated by phase separation, it should be remembered that the source profiles and histories of particle populations will very likely be a greater agent of segregation of components than 


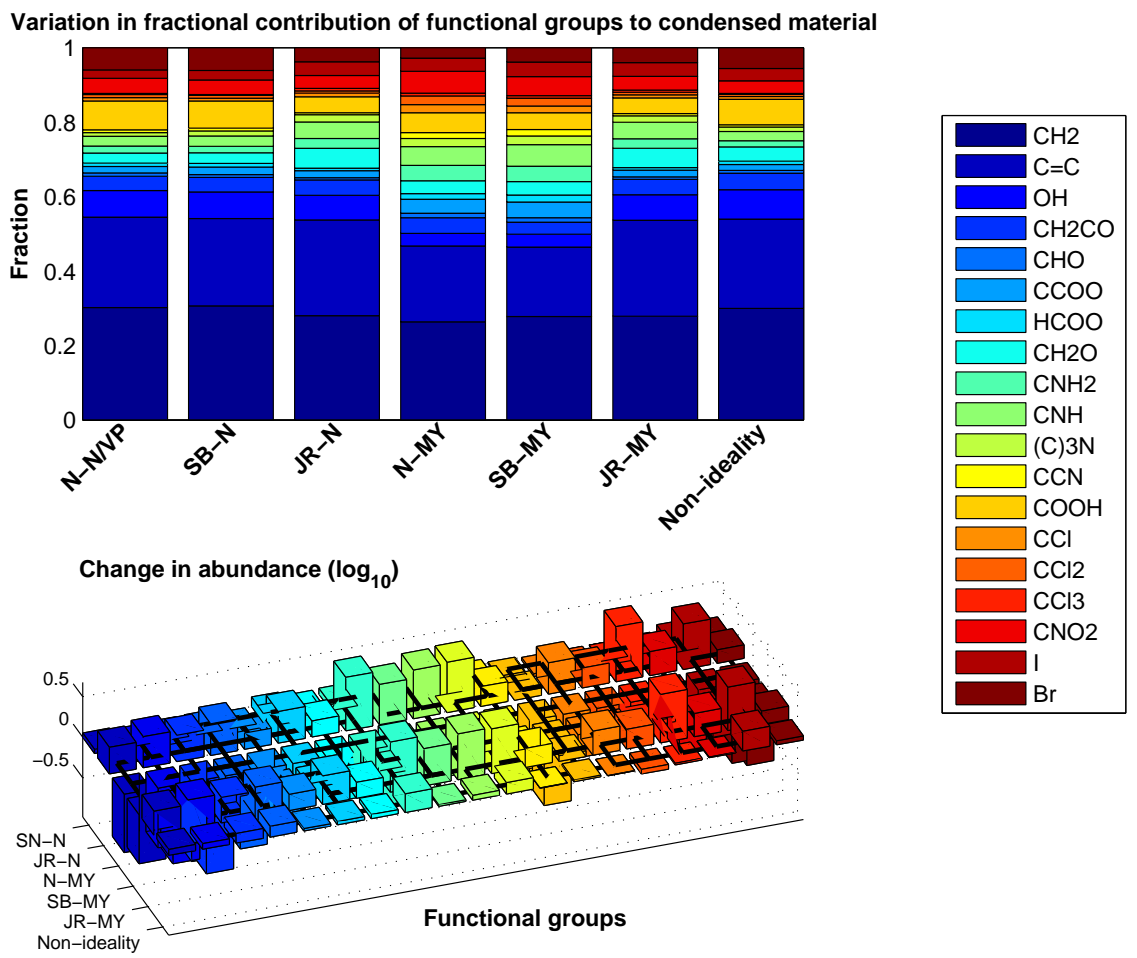

Fig. 11. Variation in fractional contribution to condensed material (top) and change in molecular abundance in the condensed phase (bottom) of each of the main UNIFAC functional groupings shown in Table 1, dependent on the property predictive technique used in the partitioning model. Ambient conditions were chosen to be $\mathrm{T}=298.15 \mathrm{~K}$ and $\mathrm{RH}=90 \%$.

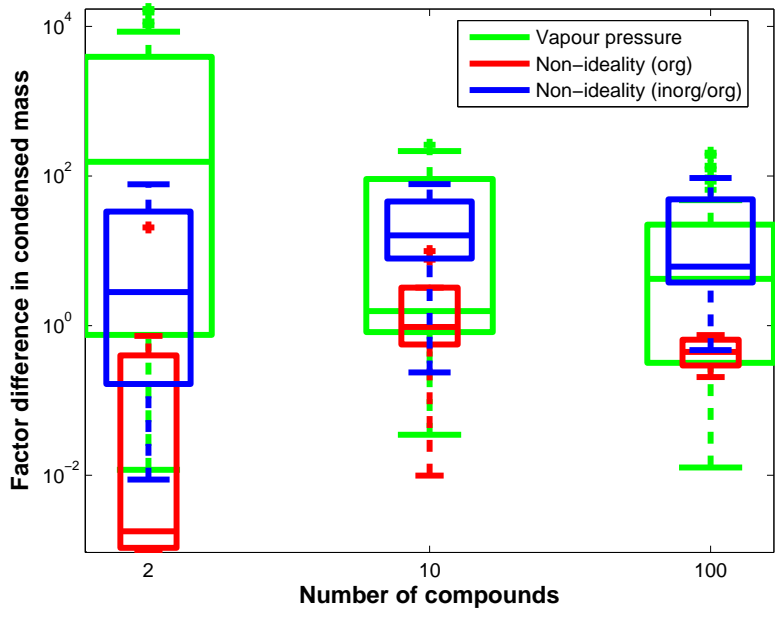

Fig. 12. An example illustration of the sensitivity of predicted total condensed organic mass across all conditions to the differences in vapour pressure predictive technique in the partitioning model (green bars, $n=45$ ), the inclusion of non-ideality for the aqueous mixture of organics(red bars, $n=9$ ) and the inclusion of nonideality for a mixture including sodium chloride at a mass ratio of $1: 1$ with the base case condensed mass (blue bars, $n=9$ ). The boxplots encompass all T- and RH-values. the phase separation predicted by thermodynamic equilibrium (i.e. component mixing state generally follows source contribution). Development of thermodynamic models that include consideration of phase separation of atmospheric components will be most useful when used to refine predictions of component separation dynamically-induced in particle populations, rather than to dictate it.

There are many limitations to the current study. Notably it is limited to aliphatic components. Whilst the very much more complicated extension to consider aromatic and cyclic components is underway, the current study serves to illustrate the high dependence on predictive techniques of secondary organic aerosol characteristics predicted by absorptive partitioning. Furthermore, the dependence of the sensitivity on the nature and mass of any absorptive core and on the total OA mass loading has not been explored, though is expected to be smaller than those explored here. It should be noted that neither consideration is likely to alter the general and quite unsurprising finding that the sensitivity of the calculations to the property predictions according to all metrics is greater for the more simplified representations. Since very much greater under- or over-prediction of all metrics is possible when a low complexity representation of the organic components is used, it will be extremely important to ensure that (i) any simplification of organic aerosol components for large-scale 
modelling applications adequately represents those present in the atmosphere and that (ii) the component properties are accurately represented by any estimation method employed in the model. This clearly indicates to the requirement for refinement and continued critical evaluation of predictive techniques as well as for appropriate laboratory data for a basis set of appropriate data covering the range of atmospheric functionality (as well as test set for technique evaluation). For vapour pressures, such data have only recently been emerging for more widely representative compounds than simple monofunctional proxies (e.g. Booth et al., 2010).

Acknowledgements. This work was carried out within the UK NERC-funded "QUantifying the Earth SysTem" (QUEST) project under the "QUest Aerosol and Atmospheric Chemistry" (QUAAC) grant number NE/C001613/1) and EU-funded "European Integrated project on Aerosol Cloud Climate and Air Quality interactions" (EUCAARI) under contract number 036833-2. DOT was supported by UK National Centre for Atmospheric Sciences (NCAS) funding. Additional support was provided by the NERC-funded "Vast Improvement" project NE/E018181/1.

Edited by: V.-M. Kerminen

\section{References}

Allan, J. D., Topping, D. O., Good, N., Irwin, M., Flynn, M., Williams, P. I., Coe, H., Baker, A. R., Martino, M., Niedermeier, N., Wiedensohler, A., Lehmann, S., Müller, K., Herrmann, H., and McFiggans, G.: Composition and properties of atmospheric particles in the eastern Atlantic and impacts on gas phase uptake rates, Atmos. Chem. Phys., 9, 9299-9314, doi:10.5194/acp-99299-2009, 2009.

Aumont, B., Szopa, S., and Madronich, S.: Modelling the evolution of organic carbon during its gas-phase tropospheric oxidation: development of an explicit model based on a self generating approach, Atmos. Chem. Phys., 5, 2497-2517, doi:10.5194/acp-52497-2005, 2005.

Barley, M., Topping, D. O., Jenkin, M. E., and McFiggans, G.: Sensitivities of the absorptive partitioning model of secondary organic aerosol formation to the inclusion of water, Atmos. Chem. Phys., 9, 2919-2932, doi:10.5194/acp-9-2919-2009, 2009.

Barley, M. H. and McFiggans, G.: The critical assessment of vapour pressure estimation methods for use in modelling the formation of atmospheric organic aerosol, Atmos. Chem. Phys., 10, 749767, doi:10.5194/acp-10-749-2010, 2010.

Bloss, C., Wagner, V., Bonzanini, A., Jenkin, M. E., Wirtz, K., Martin-Reviejo, M., and Pilling, M. J.: Evaluation of detailed aromatic mechanisms (MCMv3 and MCMv3.1) against environmental chamber data, Atmos. Chem. Phys., 5, 623-639, doi:10.5194/acp-5-623-2005, 2005.

Bloss, C., Wagner, V., Jenkin, M. E., Volkamer, R., Bloss, W. J., Lee, J. D., Heard, D. E., Wirtz, K., Martin-Reviejo, M., Rea, G., Wenger, J. C., and Pilling, M. J.: Development of a detailed chemical mechanism (MCMv3.1) for the atmospheric oxidation of aromatic hydrocarbons, Atmos. Chem. Phys., 5, 641-664, doi:10.5194/acp-5-641-2005, 2005.
Bloss, W., Lee, J., Johnson, G., Sommariva, R., Heard, D., SaizLopez, A., Plane, J., McFiggans, G., Coe, H., Flynn, M., Williams, P., Rickard, A., and Fleming, Z.: Impact of halogen monoxide chemistry upon boundary layer $\mathrm{OH}$ and $\mathrm{HO} 2$ concentrations at a coastal site, Geophys. Res. Lett., 32, L06814, doi: 10.1029/2004GL022084, 2005.

Booth, A. M., Barley, M. H., Topping, D. O., McFiggans, G., Garforth, A., and Percival, C. J.: Solid state and sub-cooled liquid vapour pressures of substituted dicarboxylic acids using Knudsen Effusion Mass Spectrometry (KEMS) and Differential Scanning Calorimetry, Atmos. Chem. Phys., 10, 4879-4892, doi:10.5194/acp-10-4879-2010, 2010.

Camredon, M. and Aumont, B.: Assessment of vapor pressure estimation methods for secondary organic aerosol modeling, Atmos. Environ., 40, 2105-2116, 2006.

Capouet, M. and Müller, J.-F.: A group contribution method for estimating the vapour pressures of ?-pinene oxidation products, Atmos. Chem. Phys., 6, 1455-1467, doi:10.5194/acp-6-1455-2006, 2006.

Clegg, S. L., Kleeman, M. J., Griffin, R. J., and Seinfeld, J. H.: Effects of uncertainties in the thermodynamic properties of aerosol components in an air quality model - Part 1: Treatment of inorganic electrolytes and organic compounds in the condensed phase, Atmos. Chem. Phys., 8, 1057-1085, doi:10.5194/acp-81057-2008, 2008.

Coe, H., Allan, J. D., Alfarra, M. R., Bower, K. N., Flynn, M. J., McFiggans, G. B., Topping, D. O., Williams, P. I., O'Dowd, C. D., Dall'Osto, M., Beddows, D. C. S., and Harrison, R. M.: Chemical and physical characteristics of aerosol particles at a remote coastal location, Mace Head, Ireland, during NAMBLEX, Atmos. Chem. Phys., 6, 3289-3301, doi:10.5194/acp-6-32892006, 2006.

Compernolle, S., Ceulemans, K., and Mller, J.-F.: Influence of non-ideality on condensation to aerosol, Atmos. Chem. Phys., 9, 1325-1337, doi:10.5194/acp-9-1325-2009, 2009.

Compernolle, S., Ceulemans, K., and Müller, J.-F.: Technical Note: Vapor pressure estimation methods applied to secondary organic aerosol constituents from $\alpha$-pinene oxidation: an intercomparison study, Atmos. Chem. Phys., 10, 6271-6282, doi:10.5194/acp-10-6271-2010, 2010.

DeCarlo, P. F., Kimmel, J. R., Trimborn, A., Northway, M. J., Jayne, J. T., Aiken, A. C., Gonin, M., Fuhrer, K., Horvath, T., Docherty, K. S., Worsnop, D. R., and Jimenez, J. L.: Field-deployable, high-resolution, time-of-ight aerosol mass spectrometer, Anal. Chem., 78, 8281-8289, 2006.

Donahue, N. M., Robinson, A. L., Stanier, C. O., and Pandis, S. N.: Coupled partitioning, dilution, and chemical aging of semivolatile organics, Environ. Sci. Technol., 40, 2635-2643, 2006.

Emmerson, K. M., Carslaw, N., Carslaw, D. C., Lee, J. D., McFiggans, G., Bloss, W. J., Gravestock, T., Heard, D. E., Hopkins, J., Ingham, T., Pilling, M. J., Smith, S. C., Jacob, M., and Monks, P. S.: Free radical modelling studies during the UK TORCH Campaign in Summer 2003, Atmos. Chem. Phys., 7, 167-181, doi:10.5194/acp-7-167-2007, 2007.

EPA: Estimation Programs Interface Suite for Microsoft Windows v3.2, United States Environmental Protection Agency, Washington, DC, USA, 2009.

Erdakos, G. B. and Pankow, J. F.: Gas/particle partitioning of 
neutral and ionizing compounds to single- and multi-phase aerosol particles. 2. Phase separation in liquid particulate matter containing both polar and low-polarity organic compounds, Atmos. Environ., 38, 1005-1013, 2004.

Fredenslund, A., Jones, R. L., and Prausnitz, J. M.: GroupContribution Estimation of Activity-Coefficients in Nonideal Liquid-Mixtures, Aiche J., 21, 1086-1099, 1975.

Fuchs, N. A. and Sutugin, A. G.: Highly Dispersed Aerosols, Ann Arbor Science, Ann Arbor, Mich., 1971.

Goldstein, A. H. and Galbally, I. E.: Known and unexplored organic constituents in the earth's atmosphere, Envir. Sci. Tech., 41, 1514-1521, 2007.

Haggerstone, A., Carpenter, L., Carslaw, N., and McFiggans, G.: Improved model predictions of $\mathrm{HO} 2$ with gas to particle mass transfer rates calculated using aerosol number size distributions, J. Geophys. Res.-Atmos., 110, D04303, doi:10.1029/ 2004JD005282, 2005

Hallquist, M., Wenger, J. C., Baltensperger, U., Rudich, Y., Simpson, D., Claeys, M., Dommen, J., Donahue, N. M., George, C., Goldstein, A. H., Hamilton, J. F., Herrmann, H., Hoffmann, T., Iinuma, Y., Jang, M., Jenkin, M. E., Jimenez, J. L., Kiendler-Scharr, A., Maenhaut, W., McFiggans, G., Mentel, Th. F., Monod, A., Prvt, A. S. H., Seinfeld, J. H., Surratt, J. D., Szmigielski, R., and Wildt, J.: The formation, properties and impact of secondary organic aerosol: current and emerging issues, Atmos. Chem. Phys., 9, 5155-5236, doi:10.5194/acp-95155-2009, 2009.

Hamilton, J. F., Lewis, A. C., Carey, T. J., and Wenger, J. C.: Characterization of polar compounds and oligomers in secondary organic aerosol using liquid chromatography coupled to mass spectrometry, Anal. Chem., 80, 474-480, 2008.

Hansen, H. K., Rasmussen, P., Fredenslund, A., Schiller, M., and Gmehling, J.: Vapor-Liquid-Equilibria by Unifac Group Contribution .5. Revision and Extension, Ind. Eng. Chem. Res., 30, 2352-2355, 1991.

Heald, C. L., Jacob, D. J., Park, R. J., Russell, L. M., Huebert, B. J., Seinfeld, J. H., Liao, H., and Weber, R. J.: A large organic aerosol source in the free troposphere missing from current models, Geophys. Res. Lett., 32, L18809, doi: 10.1029/2005GL023831, 2005.

Huffman, J. A., Docherty, K. S., Aiken, A. C., Cubison, M. J., U1brich, I. M., DeCarlo, P. F., Sueper, D., Jayne, J. T., Worsnop, D. R., Ziemann, P. J., and Jimenez, J. L.: Chemically-resolved aerosol volatility measurements from two megacity field studies, Atmos. Chem. Phys., 9, 7161-7182, doi:10.5194/acp-9-71612009, 2009

Iinuma, Y., Boge, O., Gnauk, T., and Herrmann, H.: Aerosolchamber study of the alpha-pinene/O-3 reaction: influence of particle acidity on aerosol yields and products, Atmos. Environ., 38, 761-773, 2004.

IPCC: Intergovernmental Panel on Climate Change, Fourth Assessment Report, Working Group I Report "The Physical Science Basis" Chapter 2, Cambridge University Press, 2007.

Jang, M. S. and Kamens, R. M.: Atmospheric secondary aerosol formation by heterogeneous reactions of aldehydes in the presence of a sulfuric acid aerosol catalyst, Envir. Sci. Tech., 35, 4758-4766, 2001.

Joback, K. G. and Reid, R. C.: Estimation of Pure-Component Properties from Group-Contributions, Chem. Eng. Commun., 57,
233-243, 1987.

Johnson, D. and Marston, G.: The gas-phase ozonolysis of unsaturated volatile organic compounds in the troposphere, Chem. Soc. Rev., 37, 699-716, 2008

Jonsson, A. M., Hallquist, M., and Ljungstrom, E.: Impact of humidity on the ozone initiated oxidation of limonene, Delta(3)carene, and alpha-pinene, Envir. Sci. Tech., 40, 188-194, 2006.

Kalberer, M., Paulsen, D., Sax, M., Steinbacher, M., Dommen, J., Prevot, A. S. H., Fisseha, R., Weingartner, E., Frankevich, V., Zenobi, R., and Baltensperger, U.: Identification of polymers as major components of atmospheric organic aerosols, Science, 303, 1659-1662, 2004.

Kiss, G., Tombacz, E., Varga, B., Alsberg, T., and Persson, L.: Estimation of the average molecular weight of humic-like substances isolated from ne atmospheric aerosol, Atmos. Environ., 37, 3783-3794, 2003.

Lewis, A. C., Carslaw, N., Marriott, P. J., Kinghorn, R. M., Morrison, P., Lee, A. L., Bartle, K. D., and Pilling, M. J.: A larger pool of ozone-forming carbon compounds in urban atmospheres, Nature, 405, 778-781, 2000.

Marcolli, C. and Peter, T.: Water activity in polyol/water systems: new UNIFAC parameterization, Atmos. Chem. Phys., 5, 15451555, doi:10.5194/acp-5-1545-2005, 2005.

Moller, B., Rarey, J., and Ramjugernath, D.: Estimation of the vapour pressure of non-electrolyte organic compounds via group contributions and group interactions, J. Mol. Liq., 143, 52-63, 2008.

Myrdal, P. B. and Yalkowsky, S. H.: Estimating pure component vapor pressures of complex organic molecules, Ind. Eng. Chem. Res., 36, 2494-2499, 1997.

Nannoolal, Y., Rarey, J., Ramjugernath, D., and Cordes, W.: Estimation of pure component properties Part 1. Estimation of the normal boiling point of non-electrolyte organic compounds via group contributions and group interactions, Fluid Phase Equilibr., 226, 45-63, 2004.

Nannoolal, Y., Rarey, J., and Ramjugernath, D.: Estimation of pure component properties. Part 3. Estimation of the vapor pressure of non-electrolyte organic compounds via group contributions and group interactions, Fluid Phase Equilibr., 269, 117-133, 2008.

Odum, J. R., Hoffmann, T., Bowman, F., Collins, D., Flagan, R. C., and Seinfeld, J. H.: Gas/particle partitioning and secondary organic aerosol yields, Environ. Sci. Technol., 30, 2580-2585, 1996.

Pankow, J. F.: An Absorption-Model of Gas-Particle Partitioning of Organic-Compounds in the Atmosphere, Atmos. Environ., 28, 185-188, 1994.

Pankow, J. F. and Asher, W. E.: SIMPOL.1: a simple group contribution method for predicting vapor pressures and enthalpies of vaporization of multifunctional organic compounds, Atmos. Chem. Phys., 8, 2773-2796, 2008, http://www.atmos-chem-phys.net/8/2773/2008/.

Pankow, J. F. and Chang, E. I.: Variation in the sensitivity of predicted levels of atmospheric organic particulate matter (OPM), Environ. Sci. Technol., 42, 7321-7329, doi:10.1021/es8003377, 2008.

Pankow, J. F., Seinfeld, J. H., Asher, W. E., and Erdakos, G. B.: Modeling the formation of secondary organic aerosol, 1. Application of theoretical principles to measurements obtained in the alpha-pinene/, beta- pinene/, sabinene/, Delta(3)-carene/, and 
cyclohexene/ozone systems, Environ. Sci. Technol., 35, 11641172, 2001.

Peng, C., Chan, M. N., and Chan, C. K.: The hygroscopic properties of dicarboxylic and multifunctional acids: Measurements and UNIFAC predictions, Environ. Sci. Technol., 35, 4495-4501, 2001.

Raatikainen, T. and Laaksonen, A.: Application of several activity coefficient models to water-organic-electrolyte aerosols of atmospheric interest, Atmos. Chem. Phys., 5, 2475-2495, doi:10.5194/acp-5-2475-2005, 2005.

Schwartz, S. E.: Mass-transport considerations pertinent to aqueous phase reactions of gases in liquid-water clouds, in: Chemistry of Multiphase Atmospheric Systems, edited by: Jaeschke, W., G6, NATO ASI Series, 1986.

Seinfeld, J. H., Erdakos, G. B., Asher, W. E., and Pankow, J. F.: Modeling the formation of secondary organic aerosol (SOA). 2. The predicted effects of relative humidity on aerosol formation in the alpha-pinene-, beta-pinene-, sabinene-, Delta(3)-Carene, and cyclohexene-ozone systems, Envir. Sci. Tech., 35, 18061817, 2001.

Sommariva, R., Bloss, W. J., Brough, N., Carslaw, N., Flynn, M., Haggerstone, A.-L., Heard, D. E., Hopkins, J. R., Lee, J. D., Lewis, A. C., McFiggans, G., Monks, P. S., Penkett, S. A., Pilling, M. J., Plane, J. M. C., Read, K. A., Saiz-Lopez, A., Rickard, A. R., and Williams, P. I.: $\mathrm{OH}$ and $\mathrm{HO}_{2}$ chemistry during NAMBLEX: roles of oxygenates, halogen oxides and heterogeneous uptake, Atmos. Chem. Phys., 6, 1135-1153, doi:10.5194/acp-6-1135-2006, 2006.

Stanier, C. O., Pathak, R. K., and Pandis, S. N.: Measurements of the volatility of aerosols from alpha-piniene ozonolysis, Environ. Sci. Technol., 41, 2756-2763, 2007.

Stein, S. E. and Brown, R. L.: Estimation of Normal Boiling Points from Group Contributions, J. Chem. Inf. Comp. Sci., 34, 581587, 1994

Tong, C. H., Clegg, S. L., and Seinfeld, J. H.: Comparison of activity coefficient models for atmospheric aerosols containing mixtures of electrolytes, organics, and water, Atmos. Environ., 42, 5459-5482, 2008.

Topping, D. O., McFiggans, G. B., and Coe, H.: A curved multicomponent aerosol hygroscopicity model framework: Part 2 Including organic compounds, Atmos. Chem. Phys., 5, 12231242, doi:10.5194/acp-5-1223-2005, 2005.
Wexler, A. S. and Clegg, S. L.: Atmospheric aerosol models for systems including the ions $\mathrm{H}^{+}, \mathrm{NH}_{4}^{+}, \mathrm{Na}+, \mathrm{SO}_{4}^{2-}, \mathrm{NO}_{3}^{-}, \mathrm{Cl}^{-}$, $\mathrm{Br}^{-}$, and $\mathrm{H}_{2} \mathrm{O}$, J. Geophys. Res.-Atmos., 107, 4207, doi:10. 1029/2001JD000451, 2002.

Williams, B. J., Goldstein, A. H., Millet, D. B., Holzinger, R., Kreisberg, N. M., Hering, S. V., White, A. B., Worsnop, D. R., Allan, J. D., and Jimenez, J. L.: Chemical speciation of organic aerosol during the International Consortium for Atmospheric Research on Transport and Transformation 2004: Results from in situ measurements, J. Geophys. Res.-Atmos., 112, D10S26, doi: 10.1029/2006JD007601, 2007.

Yan, W. D., Topphoff, M., Rose, C., and Gemhling, J.: Prediction of vapor-liquid equilibria in mixed-solvent electrolyte systems using the group contribution concept, Fluid Phase Equilibr., 162, 97-113, 1999.

Zhang, Q., Jimenez, J. L., Canagaratna, M. R., Allan, J. D., Coe, H., Ulbrich, I., Alfarra, M. R., Takami, A., Middlebrook, A. M., Sun, Y. L., Dzepina, K., Dunlea, E., Docherty, K., DeCarlo, P. F., Salcedo, D., Onasch, T., Jayne, J. T., Miyoshi, T., Shimono, A., Hatakeyama, S., Takegawa, N., Kondo, Y., Schneider, J., Drewnick, F., Borrmann, S., Weimer, S., Demerjian, K., Williams, P., Bower, K., Bahreini, R., Cottrell, L., Griffin, R. J., Rautiainen, J., Sun, J. Y., Zhang, Y. M., and Worsnop, D. R.: Ubiquity and dominance of oxygenated species in organic aerosols in anthropogenically-influenced Northern Hemisphere midlatitudes, Geophys. Res. Lett., 34, L13801, doi:10. 1029/2007GL029979, 2007.

Zuend, A., Marcolli, C., Luo, B. P., and Peter, T.: A thermodynamic model of mixed organic-inorganic aerosols to predict activity coefficients, Atmos. Chem. Phys., 8, 4559-4593, doi:10.5194/acp8-4559-2008, 2008.

Zuend, A., Marcolli, C., Peter, T., and Seinfeld, J. H.: Computation of liquid-liquid equilibria and phase stabilities: implications for RH-dependent gas/particle partitioning of organic-inorganic aerosols, Atmos. Chem. Phys., 10, 7795-7820, doi:10.5194/acp10-7795-2010, 2010. 